\title{
Synchronization of Fast (30-40 Hz) Spontaneous Oscillations in Intrathalamic and Thalamocortical Networks
}

\author{
Mircea Steriade, Diego Contreras, Florin Amzica, and Igor Timofeev \\ Laboratoire de Neurophysiologie, Faculté de Médecine, Université Laval, Québec, Canada G1K 7P4
}

The synchronization of fast (mainly 30 to $40 \mathrm{~Hz}$ ) oscillations in intrathalamic and thalamocortical (TC) networks of cat was studied under ketamine-xylazine anesthesia and in behaving animals by means of field potential, extra- and intracellular recordings from multiple sites in the thalamic reticular (RE) nucleus, dorsal (sensory, motor, and intralaminar) thalamic nuclei, and related neocortical areas. Far from being restricted to tonically activated behavioral states, the fast oscillations also appeared during resting sleep and deep anesthesia, when they occurred over the depolarizing component of the slow $(<1 \mathrm{~Hz})$ oscillation and were suppressed during the prolonged hyperpolarizations of RE, TC, and cortical neurons. The synchronization of fast rhythms among different thalamic foci was robust. Fast rhythmic cortical waves and subthreshold depolarizing potentials in TC neurons were highly coherent; however, the synchronization of the fast oscillation required recordings from reciprocally related neocortical and thalamic foci, as identified by monosynaptic responses in both directions. The short-range spatial confinement of coherent fast rhythms contrasted with the large-scale synchronization of low-frequency sleep rhythms. Transient fast rhythms, appearing over the depolarizing envelope of the slow sleep oscillation, became sustained when brain activation was elicited by stimulation of mesopontine cholinergic nuclei or during brain-active behavioral states in chronic experiments. These data demonstrate that fast rhythms are part of the background electrical activity of the brain and that desynchronization, used to designate brain-active states, is an erroneous term inasmuch as the fast oscillations are synchronized not only in intracortical but also in intrathalamic and TC networks.

Key words: fast rhythms; thalamus; thalamocortical; sleep; arousal; synchronization
Fast oscillations $(20-60 \mathrm{~Hz}$, mainly $30-40 \mathrm{~Hz}$ ) appear spontaneously, as part of the background electrical activity of the brain [electroencephalogram (EEG)], during states associated with tonic depolarization of cortical neurons, such as waking and rapid-cyc-movement (REM) sleep, as well as over the depolarizing phase of the slow $(<1 \mathrm{~Hz})$ oscillation during sleep and deep anesthesia (Steriade et al., 1996). The intracortical synchronization of fast activities involves synaptic linkages across vertical columns and tangential connections among various cortical foci. The possibility is open that the spontaneously occurring, synchronized cellular depolarizations at fast frequencies may underlie coherent neuronal responses to relevant sensory stimuli in waking and to internally generated drives in REM sleep (see Discussion).

The involvement of the thalamus in the genesis and synchronization of fast rhythms was debated. The initial studies on stimulusevoked fast rhythms have emphasized the purely intracortical synchronization of these oscillations in the visual cortex and their absence in the thalamic lateral geniculate (LG) nucleus (Gray et al., 1989). Subsequent experiments showed that the proportion of LG oscillatory cells in the fast frequency range is slightly higher than in the visual cortex and that one third of LG oscillatory cells display remarkable oscillations in the $50-60 \mathrm{~Hz}$ range (Ghose and Freeman, 1992). On the basis of magnetic field recordings in humans, it was proposed that coherent $40 \mathrm{~Hz}$ activities are gen-

\footnotetext{
Received Nov. 31, 1995; revised Dec. 21, 1995; accepted Jan. 5, 1996.

This work was supported by the Medical Research Council of Canada (MT-3689). D.C. and F.A. are graduate students, partially supported by the Savoy Foundation and the Fonds de Recherche en Santé du Québec. I.T. is a postdoctoral fellow. We thank G. Oakson, P. Giguère, and D. Drolet for technical assistance.

Correspondence should be addressed to Professor $M$. Steriade at the above address.

Copyright (c) 1996 Society for Neuroscience $0270-6474 / 96 / 162788-21 \$ 05.00 / 0$
}

erated by recurrent corticothalamic oscillations (Ribary et al., 1991; Llinás et al., 1994).

As to the cellular mechanisms of spontaneous fast rhythms, thalamocortical (TC) neurons display depolarization-dependent, high-frequency oscillations (Steriade et al,, 1991). A group of rostral intralaminar centrolateral (CL) neurons, with peculiar electrophysiological properties, discharge rhythmic $(\sim 40 \mathrm{~Hz})$ spike-bursts with unusually high intraburst frequencies $(800-1000$ $\mathrm{Hz}$ ), upon depolarizing current pulses or during natural states of waking and REM sleep (Steriade et al., 1993b). In view of the widespread cortical projections of thalamic intralaminar nuclei, such neurons may contribute potently to the synchronization of fast oscillations in TC networks. These results are consonant with the hypothesis that the synchronization of fast oscillations during brain-active behavioral states is mediated partially by thalamic intralaminar nuclei (Llinás and Ribary, 1993). Each major sensory and motor system may support such oscillations through a direct built-in frequency amplification in corticothalamic projections. Indeed, cortical stimulation at $30-50 \mathrm{~Hz}$ leads to a dramatic enhancement of excitatory postsynaptic potentials (EPSPs) in related thalamic cells (Lindström and Wróbel, 1990), with obvious consequences in the reciprocal TC circuit.

Despite the fact that TC cells possess voltage-dependent properties underlying fast oscillations (see above), there is no direct evidence for the participation of thalamic neurons in the synchronization processes of fast oscillations within corticothalamic networks. The present study investigated the role of intrathalamic and corticothalamic interactions in the genesis of synchronized fast spontaneous oscillations by means of cross-correlation analyses based on field potential and on extra- and intracellular recordings from related cortical and thalamic foci in acute and 
chronic experiments on cats. Data show that subthreshold depolarizing potentials of TC cells are highly coherent with fast rhythmic cortical waves and that corticothalamic synchronization of fast oscillations is best observed with recordings from reciprocally connected foci. We also demonstrate that synchronized fast oscillations appear in sensory and intralaminar TC systems during activated states, but also during the depolarizing phase of the slow sleep oscillation.

\section{MATERIALS AND METHODS}

Preparation, anesthetics, and chronic implantation. Forty-seven adult cats were used in the present study. (1) In acute experiments, the animals were anesthetized with a mixture of ketamine and xylazine $(10-15 \mathrm{mg} / \mathrm{kg}$ and 2-3 $\mathrm{mg} / \mathrm{kg}, \mathrm{i} . \mathrm{m}$.). In addition, the tissues to be incised and the pressure points were infiltrated with lidocaine. EEG was recorded continuously throughout the experiments to maintain a constant sleep-like pattern, with low-frequency, high-amplitude waves. Additional doses of anesthetics were administered at the slightest changes indicating a tendency toward an activated EEG, with decreased amplitudes and/or increased frequencies of waves. The animals were paralyzed with gallamine triethiodide and ventilated artificially by monitoring the end-tidal $\mathrm{CO}_{2}$ concentration at 3.4-3.8\%. Rectal temperature and heartbeat were monitored continuously. (2) Chronic implantation of electrodes to record the signs distinguishing various states of vigilance [EEG, electromyogram (EMG), and electro-oculogram (EOG)] was performed under ketamine (15 $\mathrm{mg} / \mathrm{kg}$, i.m.), followed by pentobarbital (25 $\mathrm{mg} / \mathrm{kg}$, i.p.). Buprenorphine $(0.03 \mathrm{mg} / \mathrm{kg}$, i.m.) was given every $12 \mathrm{hr}$ during the first postoperative day to prevent pain after surgery. An antibiotic (bicillin) was injected intramuscularly for $3 \mathrm{~d}$, postoperatively. Recordings began 1 week after surgery, with a method that keeps the head rigid without pain or pressure but allows postural adjustments and movements of limbs (Steriade and Glenn, 1982). The animals were not deprived of sleep between recording sessions.

Recording and stimulation. The field potentials were recorded through (1) coaxial electrodes inserted perpendicularly to the cortical surface, with the ring placed on the pia and the tip inserted at a depth of $0.8-1.0$ $\mathrm{mm}$, as well as in various thalamic nuclei, producing monopolar potentials (one of the leads vs a reference on the muscle) or bipolar potentials (tip-ring); and (2) arrays of four electrodes inserted at different depths in neocortical areas and in related dorsal thalamic nuclei. The various cortical areas and thalamic nuclei that have been explored are mentioned in the Results and indicated in all figures. Action potentials of cortical and thalamic cells were recorded extracellularly, simultaneously with focal field potentials, by means of tungsten microelectrodes (impedance 1-8 M $\Omega$ ). Intracellular recordings of thalamic neurons were performed in acutely prepared animals, with glass micropipettes filled with a solution of potassium acetate (impedance $25-35 \mathrm{M} \Omega$ ), after removal by suction of the overlying portion of cortex and white matter until the head of the caudate nucleus was exposed. The stability of recordings was achieved by bilateral pneumothorax, drainage of cisterna magna, and hip suspension; the hole made for recordings was filled with a solution of $4 \%$ agar. A high-impedance amplifier with active bridge circuitry was used to record and inject current into the cells. The signals were recorded on an eight-channel tape with a bandpass of $0-9 \mathrm{kHz}$, digitized at $20 \mathrm{kHz}$ for off-line computer analysis.

Spontaneous activation of the EEG occurred occasionally and only for brief periods ( $<10 \mathrm{sec}$ ). Because analyses required longer epochs of activation, bipolar stimulation of mesopontine cholinergic [pedunculopontine tegmental (PPT) or laterodorsal tegmental (LDT)] nuclei was used (trains of pulses at $300 \mathrm{~Hz}$; pulse intensity and duration: $0.05-0.5$ $\mathrm{mA}, 0.1-0.2 \mathrm{msec})$. Evoked potentials in reciprocal TC systems were used to identify thalamic and cortical foci as belonging to the same system and were elicited by stimulating with the same electrodes as those used for recording.

At the end of experiments, the animals were given a lethal dose of pentobarbital and perfused intracardially with physiological saline, followed by $10 \%$ formaldehyde. The locations of recording thalamic microelectrode tracks and stimulating thalamic and mesopontine electrodes was verified on coronal or sagittal sections $(80 \mu \mathrm{m})$ stained with thionine.

Data analysis. Intracellular, extracellular, and field potentials were treated as time series and underwent time and spectral analyses. Timerelations between two channels were disclosed with cross-correlation functions (Bendat and Piersol, 1980) that provide information about the degree of resemblance and phase sign as well as the time-lags separating the waves. The autocorrelation function indicates the main period of the oscillation (at the abscissa of the first secondary peak) and the strength of the oscillation (as a function of the number of secondary peaks visible in the autocorrelation). The spectra derived from fast Fourier transforms (FFTs) (Bendat and Piersol, 1980). Cross-spectra were calculated by applying FFTs to the cross-corrclation function; they are useful in disclosing common oscillations. To reveal the dynamics of time relations and spectral features, sequential correlation (Amzica and Steriade, 1995b) and spectral analyses were performed by dividing the different cortical and thalamic channels in successive windows and applying time and spectral procedures on each epoch. The resulting functions were deployed in three-dimensional surfaces or generated topograms. The latter may be regarded as projections of the former on the $x-y$ (horizontal) plane, in which the $z$-value is replaced with a gray scale (white for high, positive values; black for negative values).

Because the interest of this study is directed toward fast (mainly 30-40 $\mathrm{Hz}$ ) rhythms, the waves underwent digital filtering with a square window. Activities were filtered for different analyses between 10 and $100 \mathrm{~Hz}$ or between $20 / 30$ and $50 / 60 \mathrm{~Hz}$ (see legends of figures). The figures depict both the original and the filtcred traces of field potentials and intracellular activities. To avoid artifacts generated by the filtering procedure, spikes (if present) were clipped before filtering, and the filtering was applied to periods long enough $(>1 \mathrm{~min})$ to allow us to discard the extremities of the trace where edge effects may occur.

Fast frequencies appeared often as a wide-band signal modulated by other slower rhythms. This aspect was illustrated with the help of the envelope of the fast-filtered signal $(20-60 \mathrm{~Hz}$ ) (see Fig. $1 B$ ). An envelope rides over the peaks of the oscillation and is generated by the rectification of the signal (all negative values are folded over the positive ones), and the ensuing signal is low-filtered $(0-4 \mathrm{~Hz}$; the upper value is set to cover the recurrence of the bursts of fast activities).

\section{RESULTS}

The results are exposed in the following order. We first present data on the synchronization of fast oscillations (mainly $30-40 \mathrm{~Hz}$ ) resulting from field potential recordings in the thalamus and cortex, combined with intracellular recordings from various thalamic nuclei and appropriate cortical areas. In those experiments, recordings were performed within the same TC system [for example, somatosensory (SI) cortex and ventroposterior (VP) thalamus, or pericruciate motor areas 4 and 6 and ventrolateral (VL) thalamus], but we did not identify the recorded thalamic and cortical foci as reciprocally linked by means of monosynaptic responses in both (ascending and descending) directions. In later experiments, we aimed at formally identifying the sites of recordings as belonging to reciprocal corticothalamocortical loops, and after such identification procedures, we recorded the spontaneous activities from related cortical areas and thalamic nuclei. In this way we demonstrated strong corticothalamic synchronization of fast spontaneous oscillations during the depolarizing component of the slow $(<1 \mathrm{~Hz})$ oscillation. Thereafter, we present the data with stimulation of mesopontine cholinergic nuclei that activated the TC systems and induced sustained synchronization of fast oscillations in these networks. Finally, we present the results with synchronization of slow and fast rhythms during natural sleep and behavioral activation in chronically implanted animals.

\section{Database and neuronal identification}

Data collected in acutely prepared animals derived from intracellular recordings of 218 neurons located in the following cortical areas and thalamic nuclei: (1) 78 cortical cells in primary SI areas $3 \mathrm{~b}$ and 1 and 2, pericruciate motor cortical areas 4 and 6 , and suprasylvian areas 5 and 7; (2) 48 thalamic RE cells within the rostral and lateral districts of the nucleus; and (3) 92 TC neurons from VL, VP, and CL nuclei. We performed eight dual simultaneous intracellular recordings from cortical and TC cells.

Intracellularly recorded neurons retained for analyses had rest- 
ing membrane potentials $\left(V_{\mathrm{m}}\right)$ more negative than $-55 \mathrm{mV}$ and overshooting action potentials. In addition, $34 \mathrm{RE}$ cells and $48 \mathrm{TC}$ cells were recorded extracellularly. TC cells displayed short spikebursts, with a progressive increase in the duration of interspike intervals, whereas RE neurons were recognized by their prolonged spike-bursts, with an initial acceleration followed by a deceleration of spike frequency (Domich et al., 1986; Steriade et al., 1986).

Field potential recordings from cortex and thalamus were performed systematically in all experiments. In 34 cases, we recorded through arrays of four electrodes inserted at different depths in cortical areas as well as at different depths within related thalamic nuclei (for example, various areas of the visual cortex and LG thalamic nucleus, or area 5 of the suprasylvian cortex and intralaminar CL thalamic nucleus). In those cases, we were able to identify the reciprocal projections between thalamic and cortical foci by eliciting monosynaptic responses in both directions and, thereafter, to establish the synchrony between fast activities at thalamic and cortical levels.

In chronically implanted animals, field potentials were recorded from various thalamic nuclei, simultaneously with field potentials and extracellular unit recordings from suprasylvian association areas 5 and 7 as well as field potentials from areas $4,3,1,18$, and 17. Twenty-five complete sleep-waking cycles were investigated; in addition, 40 transitions from slow-wave sleep to wakefulness were analyzed.

\section{Synchronous fast oscillations in intrathalamic networks during the depolarizing phase of the slow cortical oscillation: field potential recordings from the thalamus}

Initially, we performed multi-site recordings of field potentials and intracellular activities from neocortical areas, simultaneously with field potential recordings from thalamic foci that belong, grossly, to the same sensory or motor system. In those experiments, however, the different cortical and thalamic foci were not identified formally as reciprocally linked through monosynaptic projections. The results of those experiments essentially showed (1) strong synchronization of fast oscillations (mainly $30-40 \mathrm{~Hz}$ ) between the surface-EEG, depth-EEG, and intracellularly recorded cortical neurons and (2) strong synchronization of fast oscillations among various thalamic foci, but (3) weak corticothalamic synchronization of fast oscillations when the crosscorrelations were averaged over multiple windows of $0.5 \mathrm{sec}$, corresponding to the depolarizing components of the slow oscillation $(<1 \mathrm{~Hz})$. Because of this close relationship between the fast and slow oscillations, we believe it necessary to describe the intracellular and EEG characteristics of the recently described slow rhythm as well as the similarity between the slow rhythm in animals maintained under ketamine-xylazine anesthesia and the slow rhythm during natural sleep.

Figure 1 illustrates the typical pattern of the slow cortical oscillation under ketamine-xylazine anesthesia and the dependency of fast rhythms on the depolarizing phase of the slow oscillation, and it provides a comparison between the slow oscillation under ketamine-xylazine anesthesia and the same oscillatory type in chronically implanted animals. That the pattern of the slow oscillation under ketamine-xylazine anesthesia is very similar to that occurring during resting sleep in behaving animals was also shown in a recent study on fast cortical oscillations (Steriade et al., 1996). As reported elsewhere (Steriade et al., 1994; Contreras and Steriade, 1995), the two basic components of the slow oscillation are (1) a prolonged depth-positive EEG wave associated with the hyperpolarization of pyramidal and aspiny local-circuit cortical cells, as well as the hyperpolarization of RE and TC neurons, followed by (2) a depth-negative EEG deflection associated with the depolarization of cortical and thalamic neurons; the sharp depolarization of corticothalamic neurons leads to a few spindles at $7-14 \mathrm{~Hz}$, followed by fast oscillations at $30-40 \mathrm{~Hz}$ (Fig. $1 A$ ). The spindles are triggered by the powerful drive of corticothalamic neurons during the depth-negative EEG wave, impinging upon RE neurons, which in turn impose rhythmic inhibitory postsynaptic potentials (IPSPs) onto TC cells, within spindle frequency. Indeed, the depth-negative EEG component initiates a depolarizing plateau in RE cells, with spike-bursts in the frequency range of spindles, at $7-10 \mathrm{~Hz}$ (below and Fig. 8A).

The two major components of the slow oscillation described above displayed reversed polarities at the cortical surface and depth, but the fast cortical oscillations were in phase from the surface to the deepest cortical layers (inset in Fig. 1A) (see current source density analyses and discussion of these events in Steriade and Amzica, 1996). The concomitance of fast oscillations with the prolonged depolarizing plateau of cortical neurons is demonstrated in Figure $1 A$, in which the filtered EEG traces show the diminution or suppression of fast rhythms during the hyperpolarization of SI cortical cell. Similar aspects are observed in Figure $1 B$, depicting multi-site recordings of field potentials and extracellular discharges from two cortical areas in a chronically implanted, naturally sleeping animal. The slow oscillation $(0.6-0.7$ $\mathrm{Hz}$ ) consistcd of dcpth-positive EEG waves that were synchronized among two foci within area 5 (upper traces) as well as in area 18 (lower trace). In area 5, the slowly recurring depth-positive EEG waves were associated with silenced firing of the two cells and, relatedly, the decreased envelopes of fast oscillations.

The strong intracortical synchronization of fast oscillations as well as the phase relations between cortical cellular activity and local EEG are shown further in Figure 2. Fast cortical activities were interrupted during the hyperpolarizations corresponding to the depth-positive EEG waves (Fig. $2 A$ ). The EPSPs/action potentials of SI cell were in close time-relation with the negative peaks of depth-cortical field potentials at $35-40 \mathrm{~Hz}$ (Fig. 2, $A, B$ ), thus resulting in correlations with phase opposition and very short or no time lags (Fig. $2 C$; peak values $\sim 0.4$ ). Whereas averaged cross-correlations showed clear-cut, in-phase synchronization of the two thalamic VP foci (VP1-VP2 peak $\sim 0.5$ ), the corticothalamic synchronization was rather weak (Fig. $2 C$ ).

Another experiment (Fig. 3) similarly revealed grouped fast rhythms in primary SI cortex and several VP foci, occurring concomitantly during the depolarizing phase of the slow oscillation. As shown in the intracellular recording of the SI neuron, the fast cortical oscillations appeared during the late phase of the cellular depolarization, whereas the early part of the depolarizing phase was associated with oscillations in the frequency range of spindles (asterisk). The autocorrelations of intracellular activity, cortical EEG, and thalamic field potentials indicated very similar frequencies $(\sim 35 \mathrm{~Hz})$ in all leads. The cross-correlations among the field potentials from the three VP foci demonstrated positive peaks as high as 0.8 , but the positive peaks in the cross-correlations between cortical and VP activities did not exceed 0.1 . 

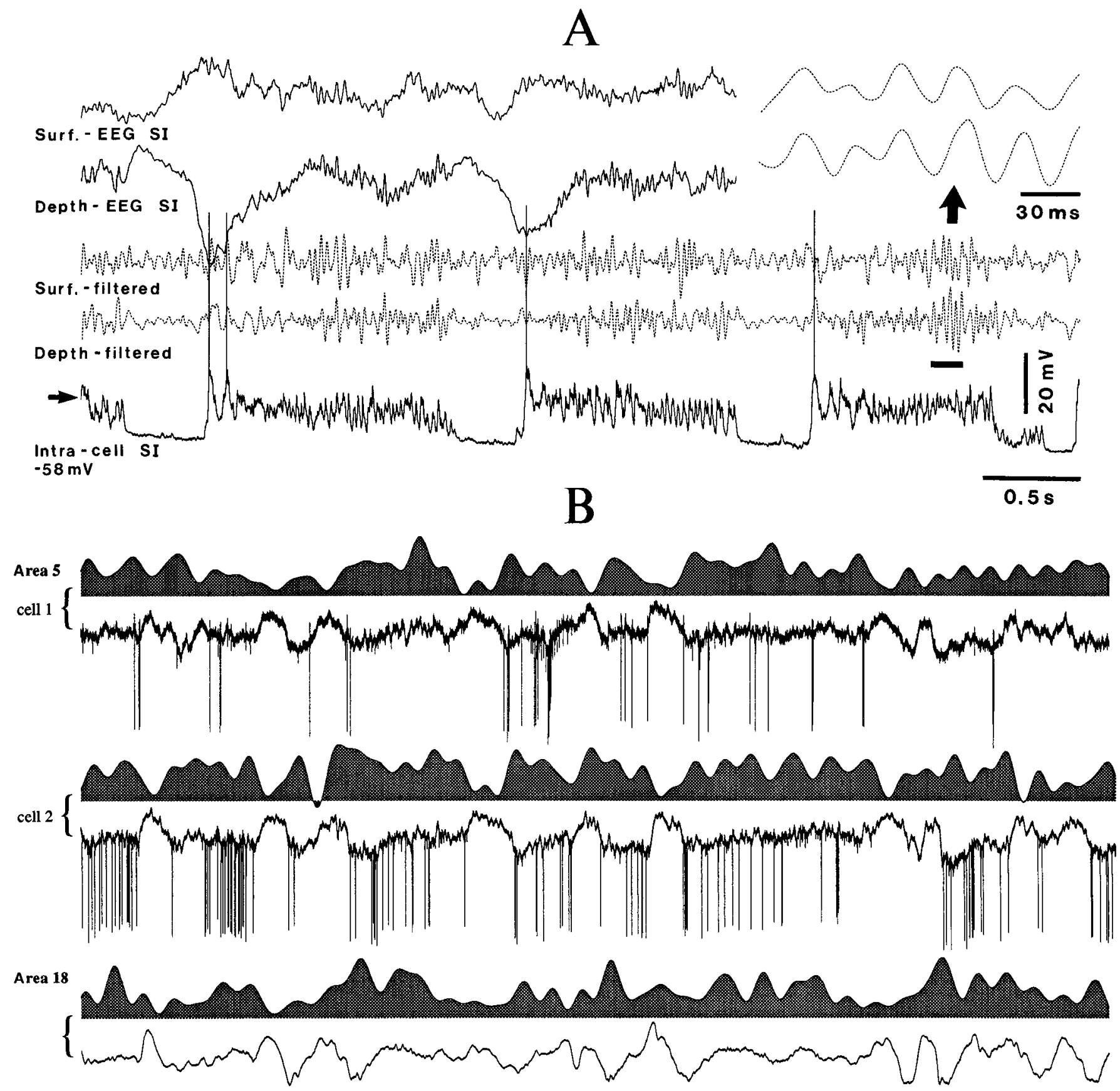

EOG

EMG

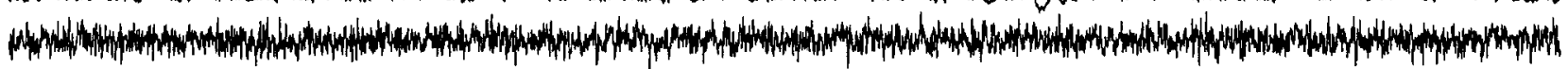

$1 \mathrm{~s}$

Figure 1. Fast oscillations $(30-40 \mathrm{~Hz})$ in cortical neurons during the depolarizing phase of the slow sleep oscillation $(<1 \mathrm{~Hz})$ under ketamine-xylazine anesthesia and in naturally sleeping animal. $A$, Slow oscillation $(0.7 \mathrm{~Hz})$ in cortical EEG from SI area and intracellularly recorded SI neuron under ketamine-xylazine anesthesia. The two dotted traces are filtered EEG activity $(10-100 \mathrm{~Hz})$. Note prolonged surface-negative (depth-positive) EEG waves associated with hyperpolarization of the SI cell. Fast oscillations occurred during the depolarizing phase of the slow oscillation and were suppressed during the hyperpolarizing phase. The in-phase fast oscillation in surface- and depth-EEG $(\sim 35 \mathrm{~Hz})$ is expanded above filtered traces (horizontal bar and arrow). $B$, Slow oscillation $(0.6-0.7 \mathrm{~Hz})$ in cortical EEG together with extracellularly recorded unit discharges and field potentials in chronically implanted, naturally sleeping animal. Simultaneous recordings of lncal field potentials and unit discharges from two foci in suprasylvian area 5, depth field potentials from area 18 of marginal gyrus, EOG, and EMG. Above the three traces from areas 5 and 18 are envelopes of fast oscillations (see Data analysis in Material and Methods). Note diminished amplitudes of fast oscillation envelopes during the depth-positive EEG waves. In this and the following figures, $V_{\mathrm{m}}$ of intracellularly recorded neurons is indicated; polarity of EEG recordings is as for intracellular recordings (positivity up). 


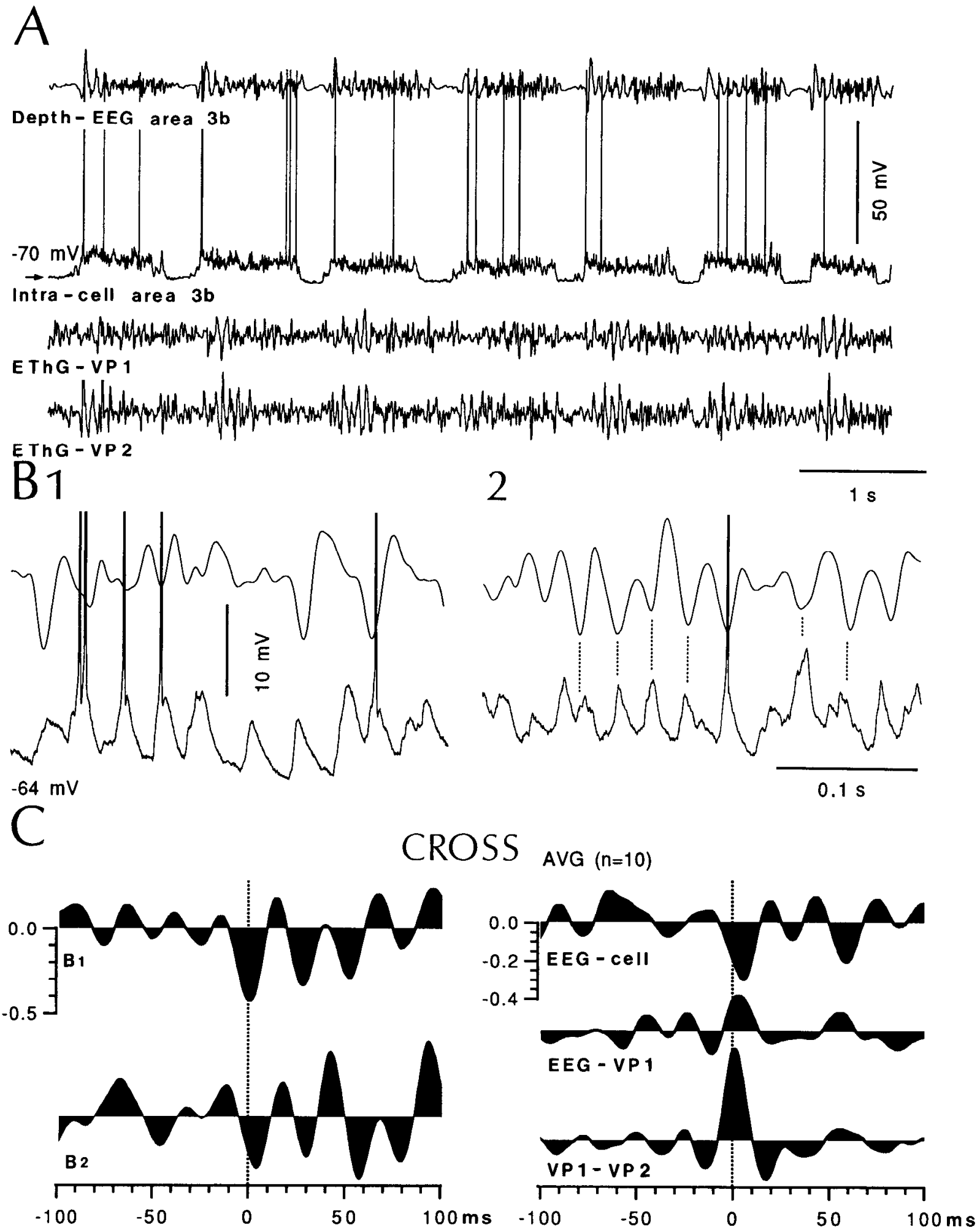

Figure 2. Intracortical and intrathalamic synchronization of fast oscillations ( $35-40 \mathrm{~Hz})$; ketamine and xylazine anesthesia. $A$, Depth-EEG from cortical area $3 \mathrm{~b}$ (SI), an intracellularly recorded cell from the same area, and electrothalamogram $(E T h G)$ from two VP foci were recorded simultaneously (EEG and EThG are filtered between 10 and $100 \mathrm{~Hz}$ ). Note that cellular depolarizations correspond to scquences of ficld potentials in EEG and EThG that are initiated by high-amplitude waves at the spindle frequency, followed by faster waves. $B$, Two depolarizing episodes ( 1 and 2$)$ are expanded to show close relations between EPSPs (up to 5-6 $\mathrm{mV}$ and occasionally leading to single spikes or spike-doublets) and depth-negative fast EEG waves (dotted lines in 2; spikes truncaled). C, Left, Cruss-currelograms (CROSS) between depth-EEG and activity of cell from $B 1$ and $B 2$ episodes, depicted above. Note oscillatory activity at $40 \mathrm{~Hz}$ with opposition of phase; no phase lag in B1, and a phase delay $<5 \mathrm{msec}$ in B2. Right, An average of 10 CROSS (episodes such as $B 1-2$ ), showing opposition of phase between depth-negative EEG and intracellular activity, in phase intrathalamic synchrony between VP1 and VP2 field potentials (peak 0.45), but weak correlation between cortical and thalamic field potentials. In this and the following figures, AUTO and CROSS designate auto- and cross-correlations. 

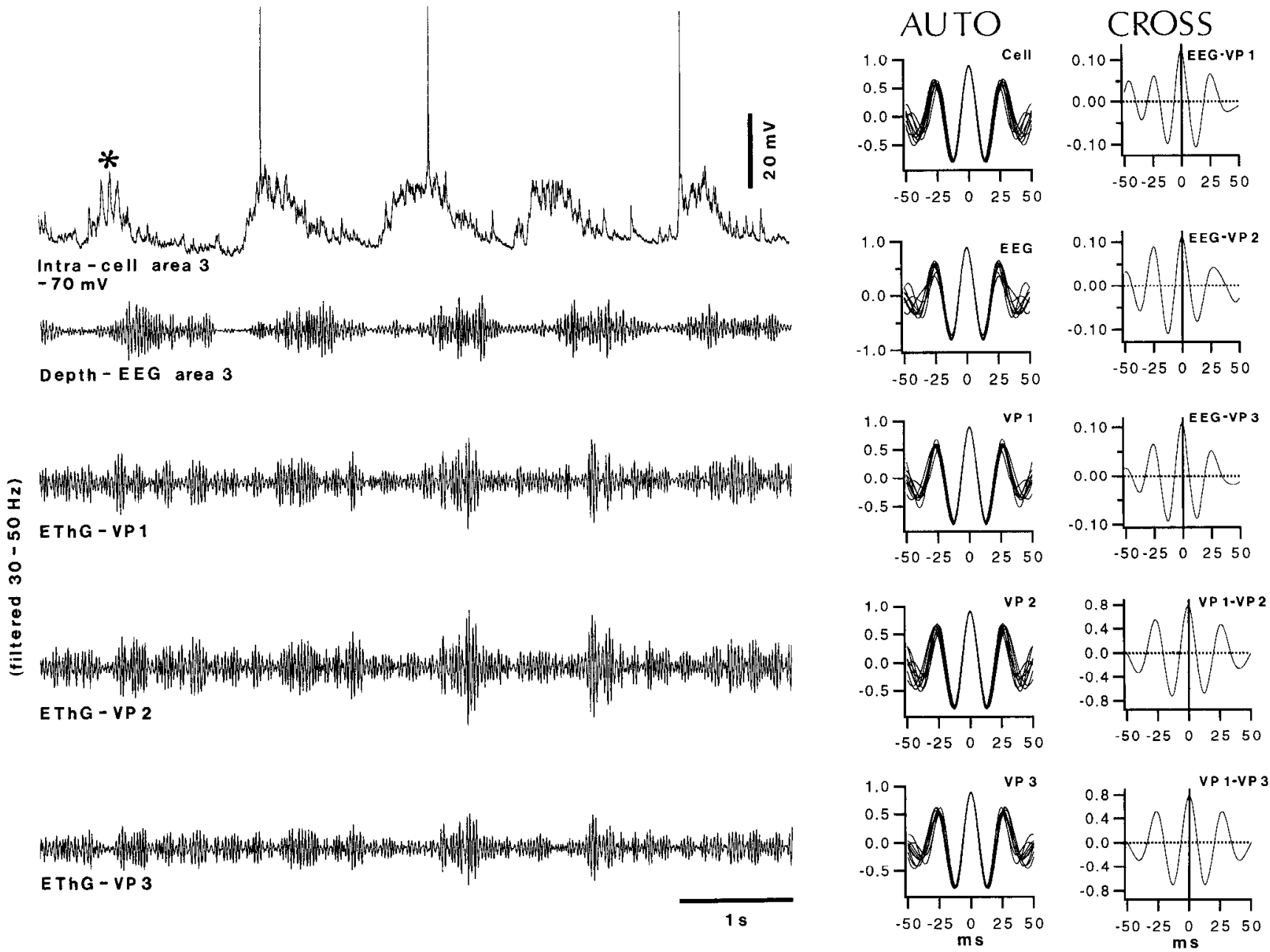

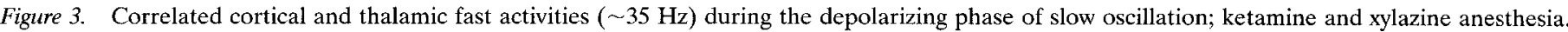

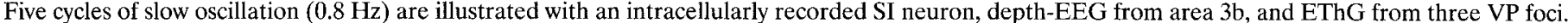

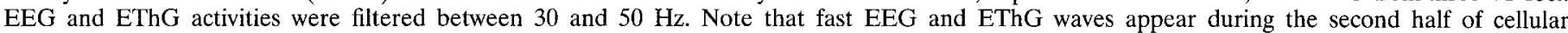

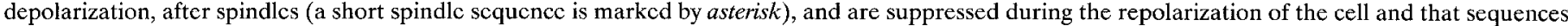

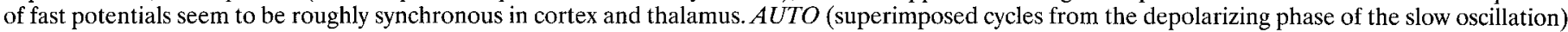

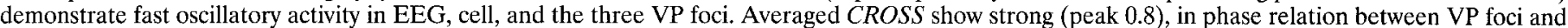
weak relation between EEG and EThG.

\section{Corticothalamic and intrathalamic synchronization of fast rhythms: intracellular recordings from TC and RE neurons}

The majority of TC cells ( $n=74 ; 80 \%$ of intracellularly recorded neurons) was hyperpolarized during the depth-positive EEG wave; at the end of the prolonged hyperpolarization (or later on, after one or repetitive IPSPs), they discharged rebound lowthreshold spikes (LTSs) crowned by a high-frequency burst of somatic action potentials. A small proportion of TC cells $(n=18)$ were depolarized and displayed tonic discharges during the depthnegative EEG component of the slow oscillation; at more hyperpolarized levels, this type of TC cell fired an LTS and spike-burst that was followed by fast, subthreshold depolarizing events.

Dual intracellular recordings from cortical and TC, neurons $(n=8)$ demonstrated the simultaneity between their hyperpolarizing phases during the slow oscillation and concomitant periods of sustained fast rhythms during short epochs of EEG activation (Fig. 4). During activated epochs (with absence of slow oscillation), the TC cells showed an increase in their background synaptic activity consisting of depolarizing potentials and fast IPSPS $\left(\sim 40 \mathrm{~Hz}\right.$ ), which were revealed at relatively depolarized $V_{\mathrm{m}}$ levels (expanded inset in Fig. 4, arrow). Whereas the fast rhythms were suppressed during the hyperpolarizing phase of the slow oscillation in both cortical and TC cells (Fig. 4, panel 1), they were uninterrupted during the brief activated epochs (panel 2). The frequencies of fast oscillations in simultaneous intracellular recordings from cortical and TC neurons could differ slightly ( $\sim 40$ $\mathrm{Hz}$ in cortical cell and $\sim 35 \mathrm{~Hz}$ in TC cell of Fig. 4).

The origin(s) of the fast recurring IPSPs in TC cells, as those illustrated in Figure 4, may be ascribed to two GABAergic cell classes: local-circuit and RE neurons. Although information about local interneurons is lacking in the present paper, we were able to record simultaneously from RE and target TC cells ( $n=$ 11). In all but one of those instances, the prolonged spike-bursts (30-50 msec or longer) of RE cells were associated typically with prolonged IPSPs in the simultaneously recorded TC neuron, lasting for 0.2-0.4 sec and having amplitudes of 8-15 mV (Fig. 5, expanded inset 1). The long durations of IPSPs as well as their amplitudes, recurring at the frequency of the slow oscillation and initiated by spike-bursts in RE cells at the same frequency (Fig. 5), 

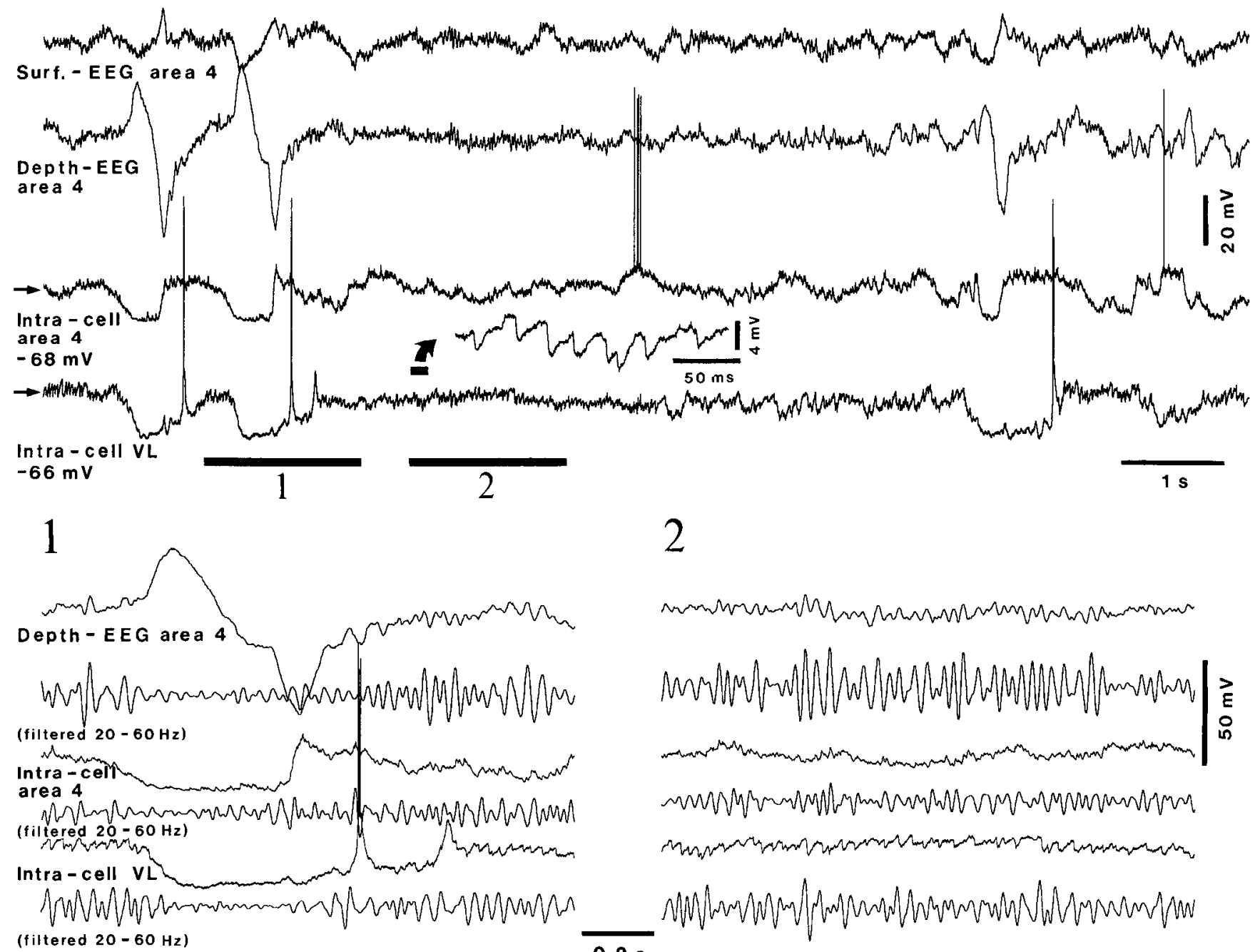

2

$0.2 \mathrm{~s}$

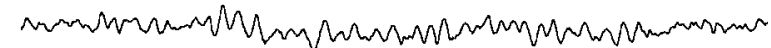

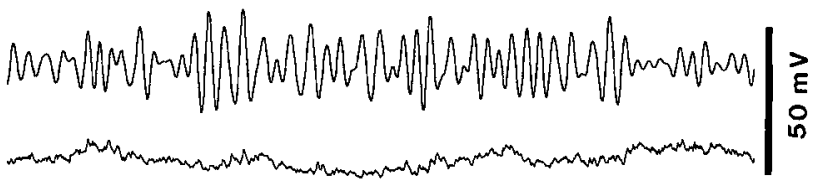

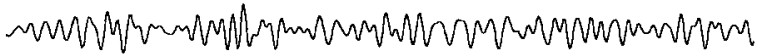

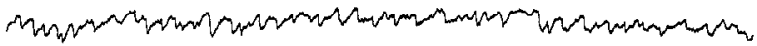

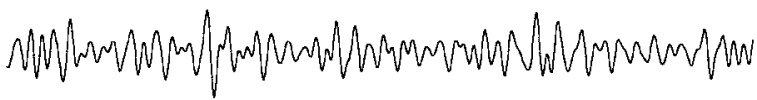

Figure 4. Dual intracellular recordings from cortical and thalamic neurons demonstrate sustained fast rhythms (35-40 Hz) during short period of EEG activation; ketamine and xylazine anesthesia. Top panel depicts simultaneous recording of surface- and depth-EEG from area 4, intracellular activity of area 4 cell, and intracellular activity from TC cell of VL nucleus. The two cycles of slow oscillation $(0.9 \mathrm{~Hz})$ were interrupted by a 6 sec period of EEG activation; slow oscillation resumed afterward. Note (extreme left) close correspondence between the prolonged depth-positive waves of the slow oscillation and long-lasting hyperpolarizations in both cortical and VL cells, followed by rebound spike-bursts in VL cell. During the activated epoch, there was an increase in synaptic activity with a mixture of EPSPs and IPSPs. The part marked by horizontal bar above the VL trace is expanded above (arrow) to show short-lasting, rhythmic IPSPs at $40 \mathrm{~Hz}$. Two periods ( $I$ and 2), the first from the slow oscillation and the second from the activated epoch, are expanded below with depth-EEG and two intracellularly recorded neurons (below each trace, filtered activity between 20 and $60 \mathrm{~Hz}$ ). Note in 1 that fast rhythms are diminished, up to suppression, during the prolonged hyperpolarizing component of the slow oscillation. Also note sustained fast rhythms during the activated epoch (2).

are very different from those of the short-lasting $(10-20 \mathrm{msec})$, small amplitude $(2-3 \mathrm{mV})$, fast-recurring IPSPs depicted in Figure 4 (see Discussion).

The fast oscillations extended continuously in cortical, TC, and RE recordings during short periods of brain activation (panel 2 in Fig. 5), but they were interrupted at all these levels during the prolonged depth-positive EEG wave (panel 3 in Fig. 5). Importantly, the EPSPs leading to action potentials in the TC cell were closely related to the peak negativities of fast $(40 \mathrm{~Hz})$ field potentials recorded from the depth of the corresponding cortical area (expanded inset of panel 2 in Fig. 5). Cross-correlations between depth-EEG waves and thalamic EPSPs (from periods in which action potentials were absent) confirmed the above aspect by demonstrating fast $(\sim 40 \mathrm{~Hz})$, synchronized corticothalamic activities in opposition to phase and lime lags $<2 \mathrm{msec}$ (Fig. 5).

A small proportion of TC cells $(n=18 ; 20 \%)$ were depolarized during the depth-negative EEG wave of the slow oscillation and displayed tonic activity consisting of full action potentials or subthreshold depolarizing events recurring at fast frequencies: $50-80 \mathrm{~Hz}$ (Fig. 6). At a $V_{\mathrm{m}}$ more positive than $-60 \mathrm{mV}$, the depolarizing phase of the slow oscillation $(0.7-0.8 \mathrm{~Hz})$ in this VL cell was initiated occasionally by one or two spike-bursts or spike-doublets, but thereafter prolonged trains of single spikes, lasting for $0.5 \mathrm{sec}$ and reaching frequencies up to $80 \mathrm{~Hz}$, were observed (Fig. 6A). The spike-doublets that initiated the depolarizing phase arose from after-depolarizing humps, which were obvious in subsequent single-action potentials (expanded trace in Fig. $6 \mathcal{A}$ ). At more negative $V_{\mathrm{m}}$, an LTS leading to spike-doublet or full-blown spike-burst followed the long-lasting hyperpolarization, corresponding to the depth-positive EEG wave; thereafter, fast depolarizing events at a frequency of $50 \mathrm{~Hz}$ extended over a period of $0.2 \mathrm{sec}$ (Fig. $6 B$ ). In most cases $(n=12)$, these events 


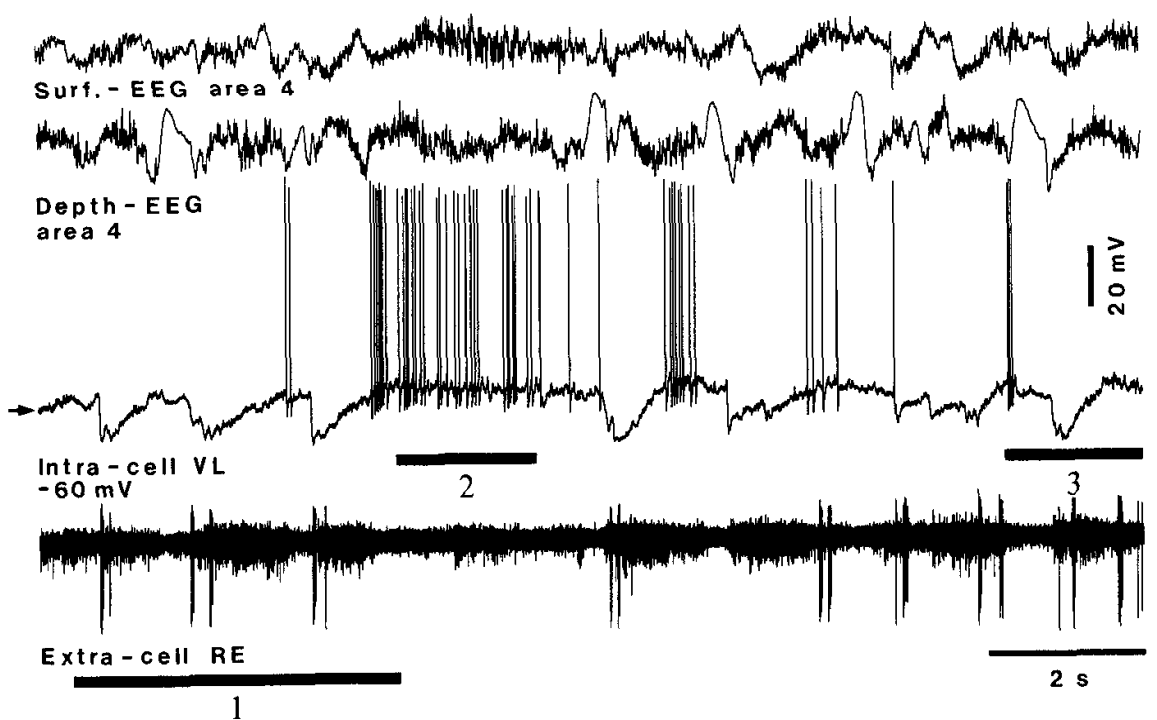

1

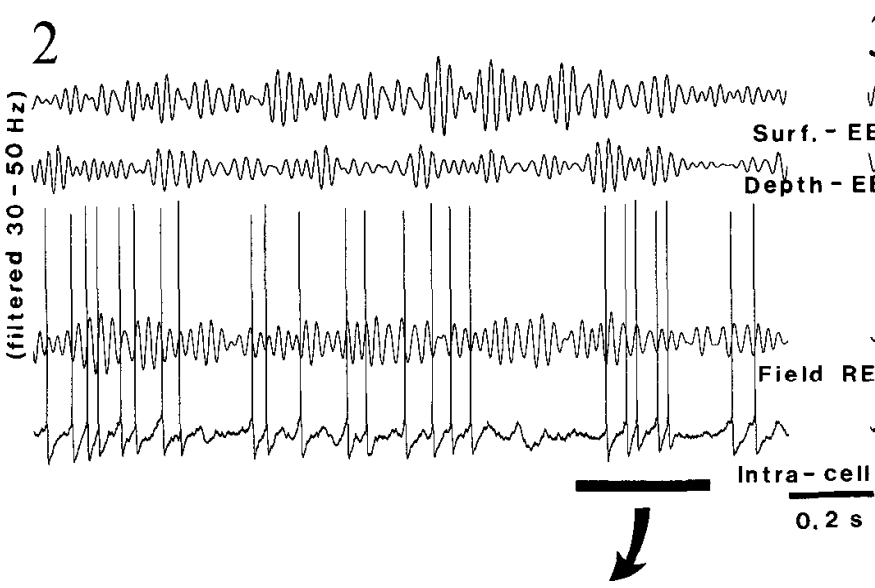

3

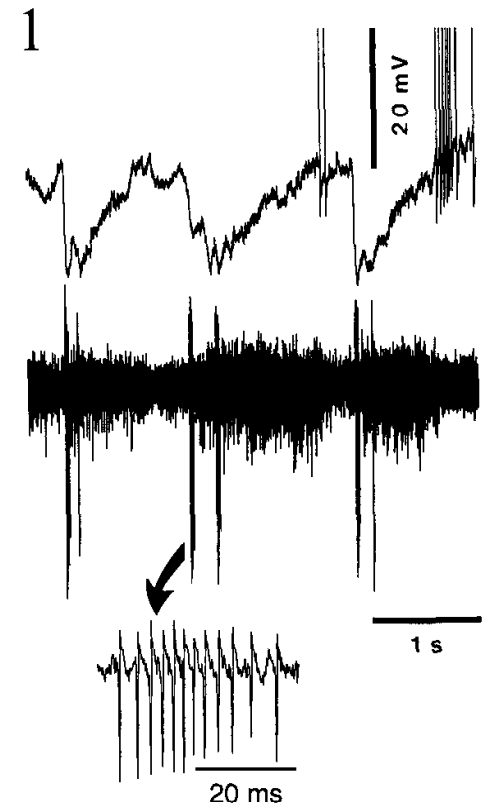

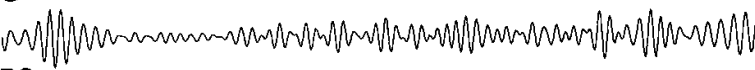

EG
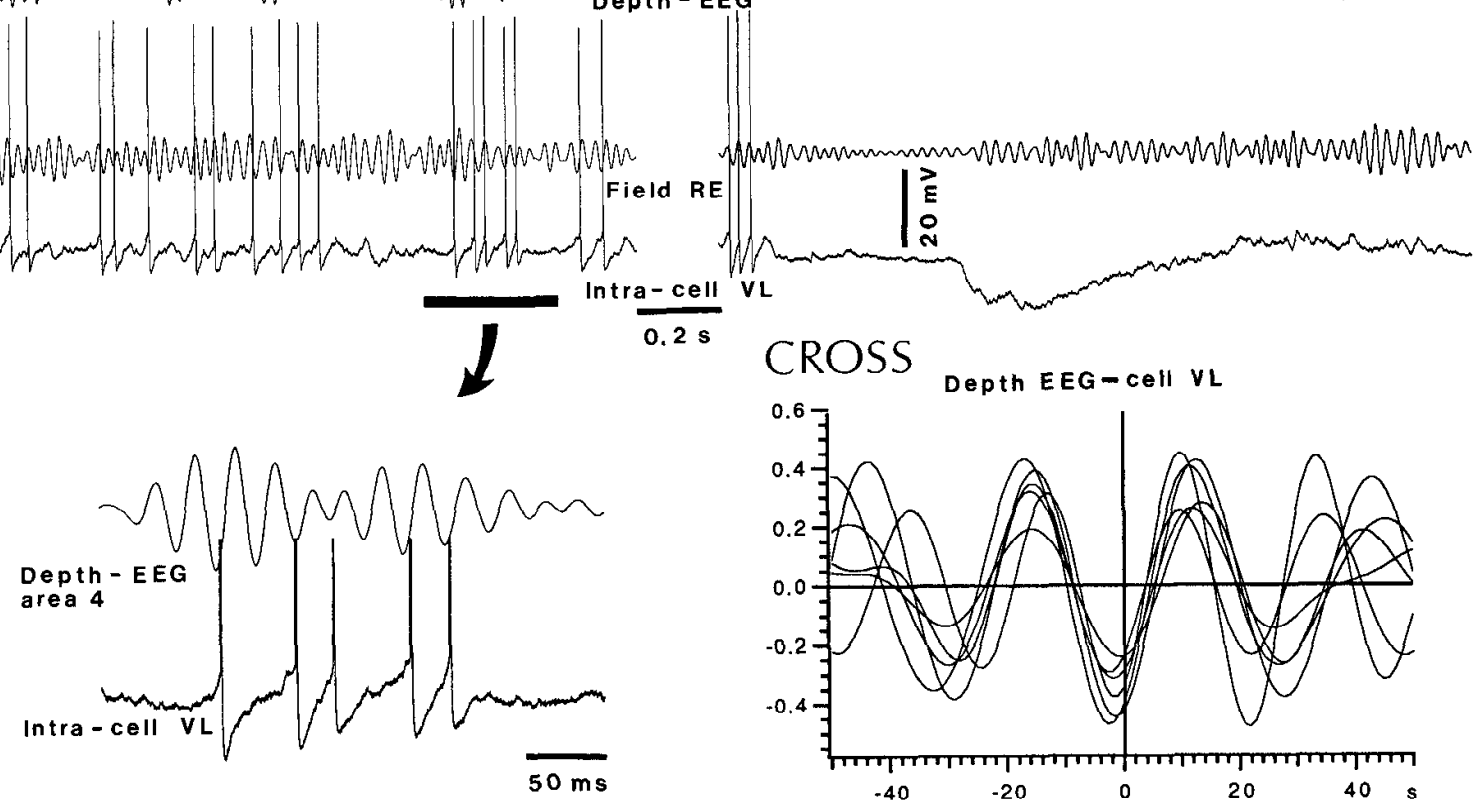

Figure 5. Brief episodes of tonic activation are accompanied by sustained and correlated fast rhythms $(40 \mathrm{~Hz})$ in cortex and intracellularly recorded TC cell; ketamine and xylazine anesthesia. Top left, Four traces represent simultaneous recording of surface- and depth-EEG from precruciate area 4, intracellular activity of TC cell from the VL nucleus, and extracellular discharges of rostrolateral RE cell. EEG, VL, and RE cells display a slow oscillation $(0.7-0.8 \mathrm{~Hz})$ consisting of long-lasting, depth-positive EEG waves, leading to sharp depth-negative EEG potentials, related to the initiation of biphasic, long-lasting IPSPs in VL cell. The IPSPs are coincident with (and presumably generated by) spike-bursts in RE neuron. Panel marked by 1 is expanded at right. One spike-burst of RE cell is expanded below (arrow) to show its high frequency $(450 \mathrm{~Hz})$ and typical accelerando-decelerando pattern. Panels 2 (from activated epoch) and 3 are expanded below, with filtered activities $(30-50 \mathrm{~Hz})$ from surface- and depth-EEG as well as from local field potentials recorded by the microelectrode that picked up discharges of RE cell, and with intracellular activity of VL neuron. Part marked by horizontal bar in 2 is expanded further below (arrow). Note relation between depolarizations leading to action potentials in VL cell and depth-negative waves in cortical EEG, at a frequency of $40 \mathrm{~Hz}$. CROSS is taken from a period of activity without action potentials in VL cells and shows clear-cut relation, with opposition of phase, between depth-EEG and intracellularly recorded VL neuron.

recorded from TC cells in the VL nucleus were typical EPSPs, according to their slope, duration, and voltage-dependency, and they strikingly resembled the EPSPs evoked in the same neurons by stimulating the cerebellothalamic pathway; however, in the remaining six $\mathrm{TC}$ neurons, the pattern of depolarizing events suggested that they represent all-or-none fast prepotentials (Steriade et al., 1991).

In keeping with the results from TC cells, the fast oscillations of 

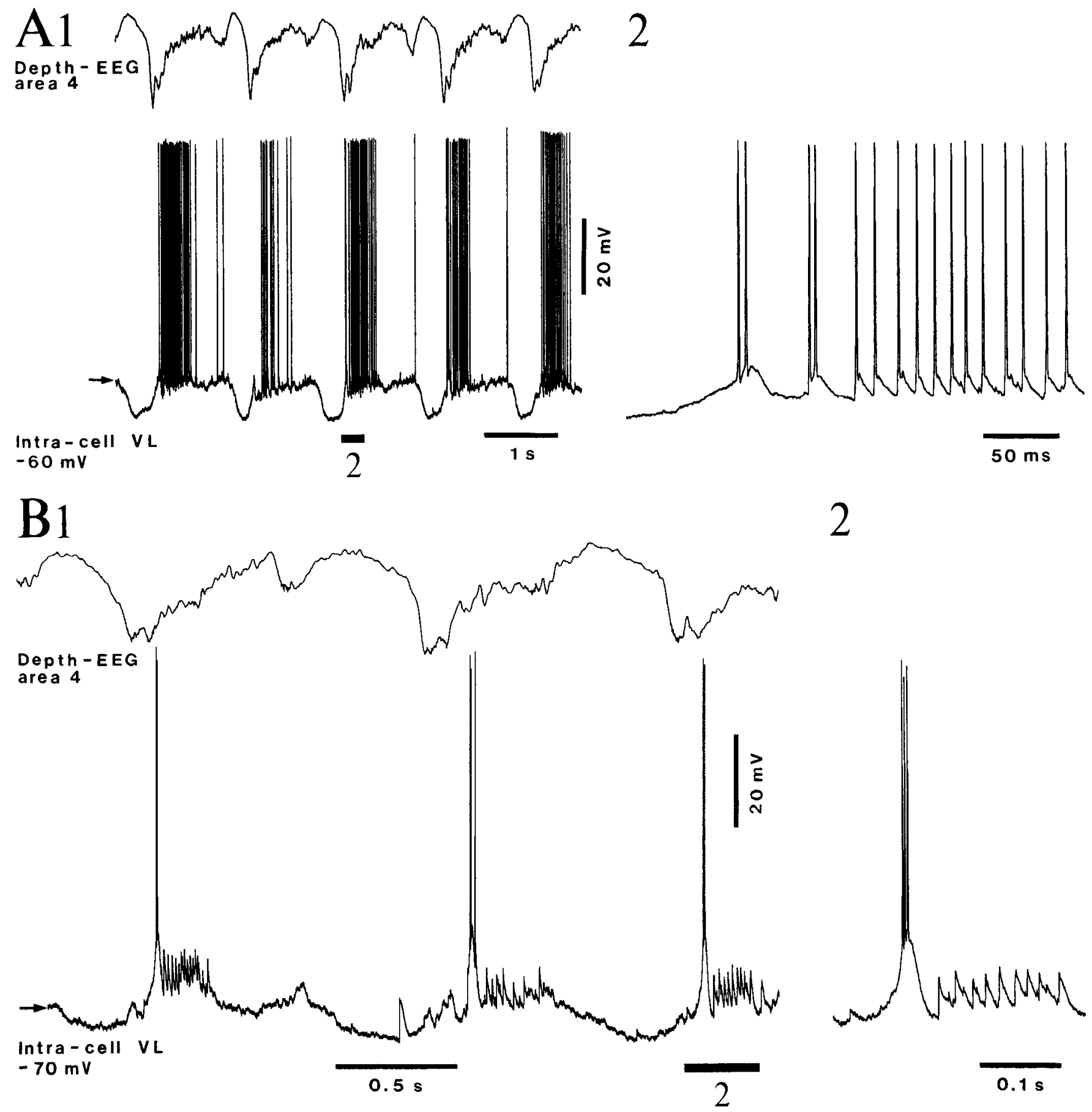

Figure 6. Tonic, fast activity during the depolarizing phase of the slow oscillation in TC cells; ketamine and xylazine anesthesia. $A 1$, Depth-EEG and intracellular recording from TC cell in VL nucleus during the slow oscillation $(0.7-0.8 \mathrm{~Hz})$ showing strict relations between depth-positive EEG and hyperpolarization of TC neuron, followed by tonic firing at $\sim 80 \mathrm{~Hz}$. Part expanded by horizontal bar is expanded at right $(A 2)$. B1, Fast (50-60 $\mathrm{Hz})$ subthreshold events in TC neuron from the VL nucleus during the depolarizing phase of the slow oscillation $(0.9 \mathrm{~Hz})$. Three cycles of the slow oscillation are depicted with depth-EEG from motor cortex and intracellular recording of VL neuron. The cycle marked by horizontal bar is expanded at right (B2).

RE cells were confined within the depolarizing phase of the slow cortical oscillation and were selectively suppressed during the hyperpolarizing phase (Fig. $7 A$ ). This was established by simultaneous intracellular recording of cortical cells and extracellular recording of RE neurons $(n=22)$. In such experiments, we also recorded the local field potentials in the RE nucleus, with the same tungsten microelectrode that picked up the action potentials, and were able to show that the fast focal waves in the RE nucleus $(\sim 45 \mathrm{~Hz})$ virtually disappeared toward the end of the depth-positive EEG cortical wave, associated with the hyperpolarization of the cortical neuron and the silenced firing of the RE cell (Fig. 7).

The simultaneous recording of EEG activity in the depth of motor cortical area 4, intracellular activity of an RE neuron from the rostrolateral district, and extracellular activities of RE cells ( 2 $\mathrm{mm}$ apart from the impaled RE neuron) and TC cells from VL 


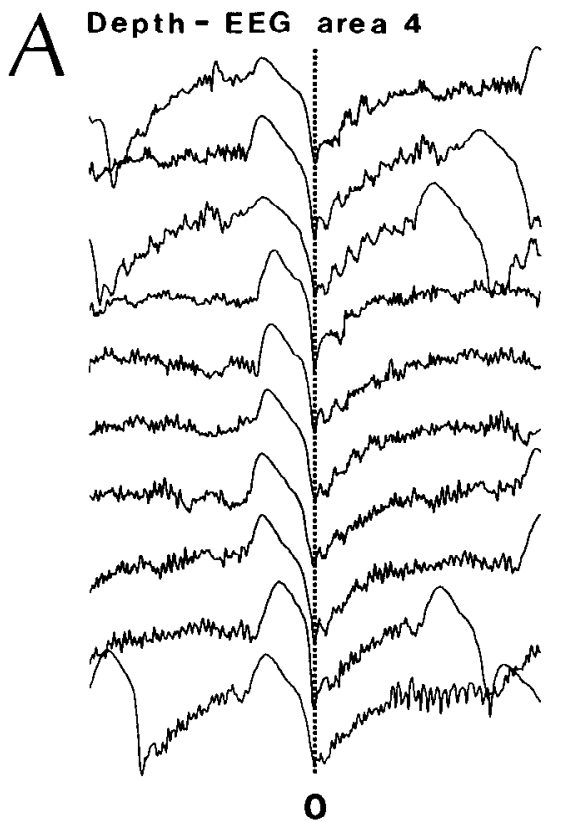

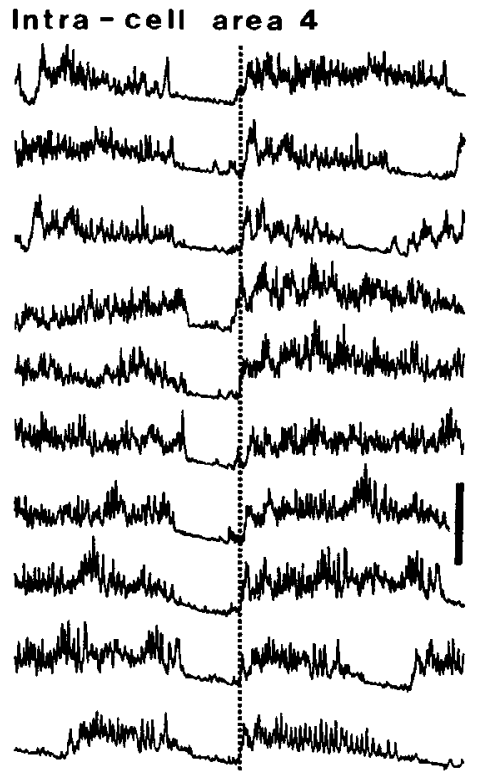

0

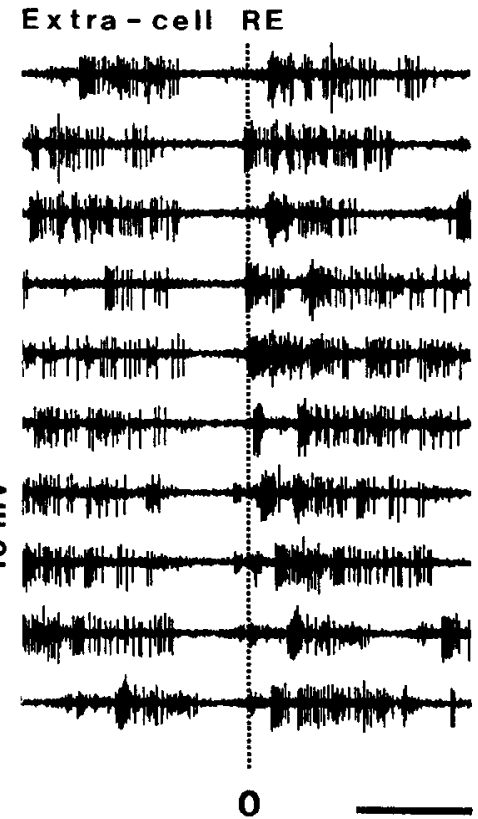

$0.5 \mathrm{~s}$

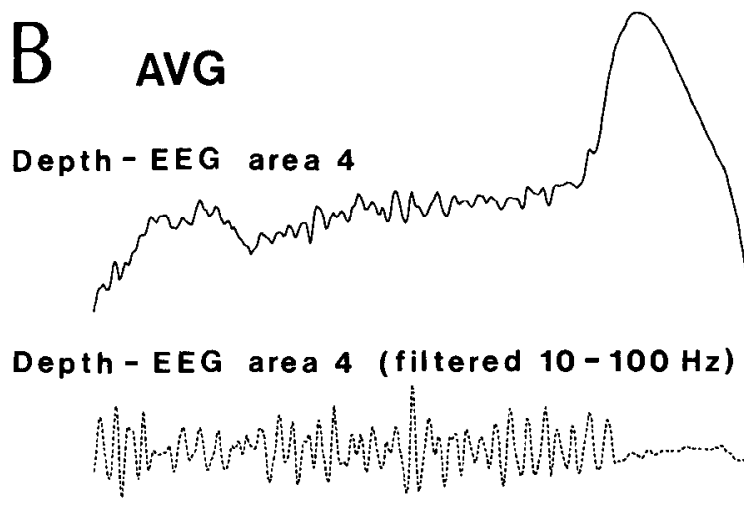
Intra-cell area 4

Focal waves RE (filtered $10-100 \mathrm{~Hz}$ )

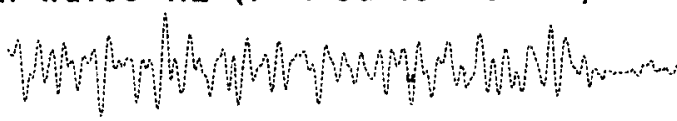

RE - cell histogram
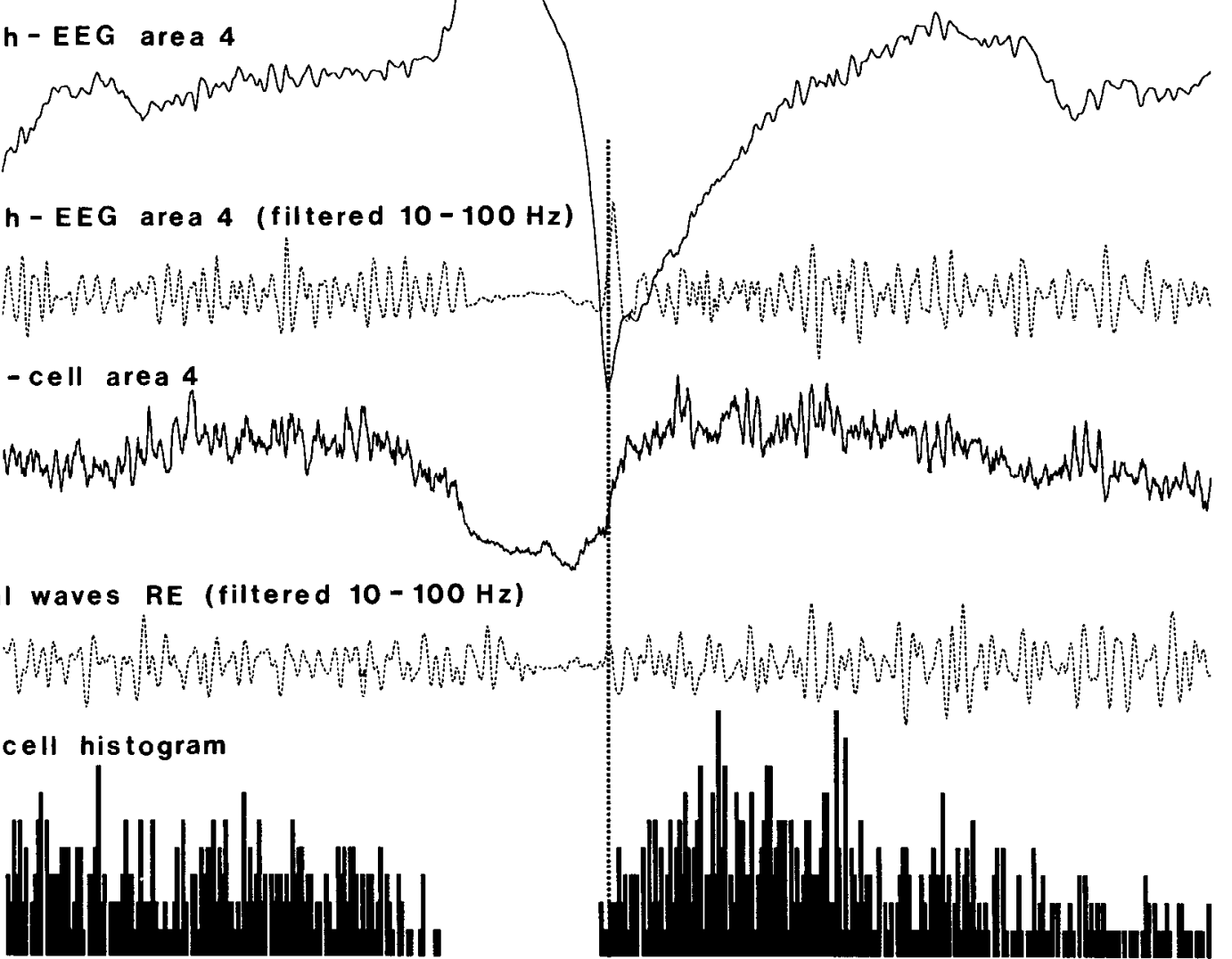

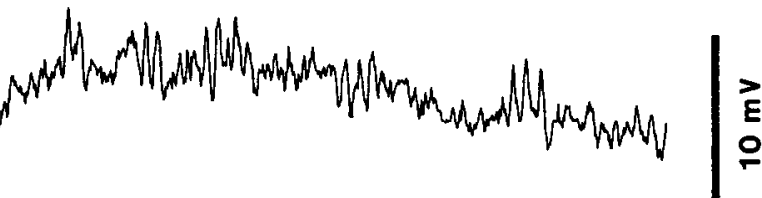

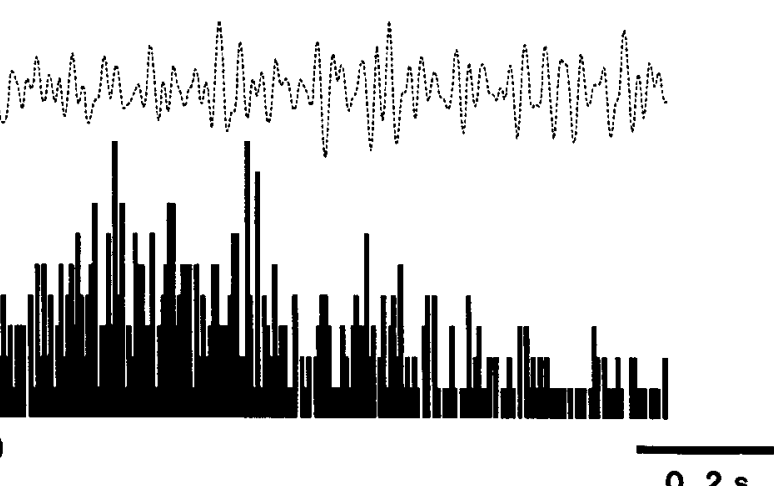

$0.2 \mathrm{~s}$

Figure 7. Fast oscillations ( $40-45 \mathrm{~Hz}$ ) are suppressed in cortical and RE neurons during the depth-EEG positive wave of the slow oscillation; ketamine and xylazine anesthesia. $A$, Simultaneous recording of depth-EEG waves from area 4, intracellular activity of cortical neuron from area 4 , and extracellular activity of RE cell from the rostral pole of the nucleus. Each column was centered on time 0 (dotted lines), represented by the sharp depth-negative EEG deflection (following the prolonged depth-positive phase of the slow oscillation), which was used as reference for aligning EEG, intracellularly recorded area 4 neuron, and extracellularly recorded RE neuron. $B$, Average $(A V G)$ of 10 traces depicted in $A$, plus filtered EEG trace, filtered local field potentials recorded in the RE nucleus by the same microelectrode that picked up the cellular discharges, and peri-event histogram of discharges of RE-cell. 
nucleus (Fig. 8) allowed us to demonstrate further the concomitance between groups of fast waves at $35-40 \mathrm{~Hz}$ in related cortical, RE, and dorsal thalamic territories. During a period in which the slow oscillation $(0.8 \mathrm{~Hz})$ was continuous, filtered $(20-60 \mathrm{~Hz})$ traces from all recordings showed grouped fast oscillations during the depolarizing component of the slow oscillation and their diminution up to suppression during the depth-positive EEG wave associated with the hyperpolarization of the RE neuron and silenced firing in the extracellularly recorded RE and VL cells (Fig. 8A). The waxing and waning sequences of fast potentials at $35-40 \mathrm{~Hz}$ occupied the second part of the depolarizing phase of the slow oscillation (see especially the third to fifth slow oscillatory cycles in Fig. $8 A$ ), only after the termination of the spindle oscillation that was associated with spike-bursts at $7-10 \mathrm{~Hz}$ in the intraccllularly recorded RE neuron and that occupicd the first half of the depolarizing phase in each oscillatory cycle. Similarly, the fast oscillation of field potentials was more pronounced during the second half of the depolarizing envelope in the extracellular recordings from $R E$ and VL nuclei (see especially the first four slow oscillatory cycles in Fig. 8A). During the slow oscillation, fast activities were rhythmically interrupted during the prolonged hyperpolarizing component, whereas during short EEG-aclivated epochs, the intracellularly recorded RE neuron was tonically depolarized, and the filtered $(30-50 \mathrm{~Hz})$ field potentials were almost continuous (Fig. $8 B$ ). Note the precursor changes in firing pattern of VL neuron and associated field potential activities, $\sim 3$ sec before generalized activation signs in cortical EEG and intracellular RE cell.

\section{Synchronization of fast oscillations in physiologically identified, reciprocally related cortical and thalamic neuronal pools}

Because we did not succeed in the initial experiments to obtain clear-cut evidence for synchronized fast oscillations in corticothalamic networks (see again cross-correlations in Figs. $2 C$ and 3 showing weak or negligible synchrony), we hypothesized that fast activities are not synchronized widely but are distributed across specific, related pools of thalamic and neocortical neurons that remained unidentified in those experiments. We thus inserted arrays of multiple stimulating/recording coaxial electrodes in cortical areas and appropriate dorsal thalamic nuclei and, before considering the possible synchrony among them, physiologically identified their reciprocal relations by means of monosynaptic responses in both ascending and descending directions.

Figure 9 shows a typical example from this series of experiments $(n=34)$. Because many so-called specific thalamic nuclei project well beyond primary cortical projection areas, we also wanted to determine whether the TC synchrony of fast oscillations transcends the conventional "specific" systems. For example, it is known from morphological and physiological studies that at least some parts of the thalamic LG nucleus, in addition to striate and peristriate cortices, project to the lateral suprasylvian cortex (Gilbert and Kelly, 1975; Raczkowski and Rosenquist, 1980; Tong et al., 1982), where area 21 is located (Sherk, 1986). In our experiments, single-shock stimulation of area 21 evoked short-latency $(1.2-1.5 \mathrm{msec})$ responses in the same area and similar shortlatency responses in the ipsilateral LG nucleus. Also, LG stimulation evoked short-latency $(<1.5 \mathrm{msec}$ ) responses in area 21 (Fig. $9 A$ ). By recording four foci at the surface and various depths of cortical area 21 and another four foci in the LG nucleus, which were identified as reciprocally connected, we obtained evidence that during the depolarizing phase of the slow oscillation, se- quences of fast $(30-40 \mathrm{~Hz})$ field potentials are grouped together in the cortex and thalamus (Fig. 9B). The four cortical foci displayed in-phase fast waves, from the surface to the deepest layer, and similar in-phase fast activities were seen in the LG nucleus, although the frequency of thalamic waves was slightly higher $(40 \mathrm{~Hz})$ than that of cortical ones $(35 \mathrm{~Hz})$. This difference was reflected in the cross-correlation between area 21 and LG, showing slightly higher frequency in the thalamus but demonstrating TC correlation, with a peak close to or exceeding 0.4 . Similar results on the synchrony of fast oscillations in reciprocal $\mathrm{TC}$ systems were obtained by simultaneous recordings in cortical area 5 and thalamic intralaminar CL nucleus (see below).

\section{Sustained corticothalamic synchronization of fast rhythms during brainstem-induced activation}

The relations between cortical and thalamic fast activities was explored further by simultaneous recordings of field potentials during slowly oscillatory and tonically activated epochs. The latter were elicited by stimulating PPT or LDT mesopontine cholinergic nuclei whose thalamic-projecting neurons are known to trigger and maintain tonic activation processes in TC systems (Steriade et al., 1990). Because one of the major thalamic targets receiving excitatory impulses from mesopontine neurons is corticalprojecting neurons of the rostral intralaminar CL nucleus (Steriade and Glenn, 1982; Paré et al., 1988), we recorded simultaneously from four foci in CL nucleus and four foci in suprasylvian area 5 , toward which CL preferentially projects (Steriade and Glenn, 1982; Jones, 1985). Single stimuli applied to PPT elicited an initially negative field potential throughout the thalamic $\mathrm{CL}$ nucleus, which had a latency onset of $2.5 \mathrm{msec}$ (Fig. 10B), compatible with a monosynaptic excitation; the antidromic response latencies of PPT-CL neurons range between 1 and $3.5 \mathrm{msec}$ (Steriade et al., 1990). The PPT-evoked response in cortical area 5 had an initial positive component that did not reverse its polarity across the depth, followed by a depth-negative (surface-positive) wave (Fig. 10B).

After having identified this PPT-CL-cortical circuit, we recorded spontaneously occurring field potentials from all four CL foci and four cortical foci during epochs with continuous slow oscillations and epochs in which a high-frequency $(300 \mathrm{~Hz})$ pulsetrain to the PPT nucleus suppressed the slow oscillation and replaced it by sustained fast activities (Fig. 10A). During the slow oscillation, fast rhythms occurred only during the depth-negative (surface-positive) cortical component, after a sequence of waves in the upper frequency range of spindles that were visible in both cortical and thalamic recordings (see especially the second oscillatory cycle in the filtered traces of Fig. 101; similar aspects may be seen in Figs. $1 A, 8 A$ ). During the PPT-elicited activation, the fast rhythms were sustained for a period of $\sim 5 \mathrm{sec}$, after which the slow oscillation resumed (Fig. 10A). These two epochs, with slow oscillation (1) and sustained fast activities (2) are analyzed further in Figure 11. Panel 1 shows the presence of fast cortical and thalamic rhythms $(20-30 \mathrm{~Hz})$ during the depth-negative EEG component (darker trace, middle) and their reduction or absence during the preceding and following depth-positive component (left and right). The cross-correlation hetween area 5 and CL activities shows variable relations, and the cross-spectrum in the FFT panel shows two equal peaks at $20 \mathrm{~Hz}$ and $30 \mathrm{~Hz}$. On the other hand, during the activated epoch elicited by PPT stimulation (panel 2), fast rhythms were continuous, the cross-correlation between cortical and thalamic activities became more regular, and the peak at $30 \mathrm{~Hz}$ in the cross-spectrum prevailed over that at $20 \mathrm{~Hz}$. 


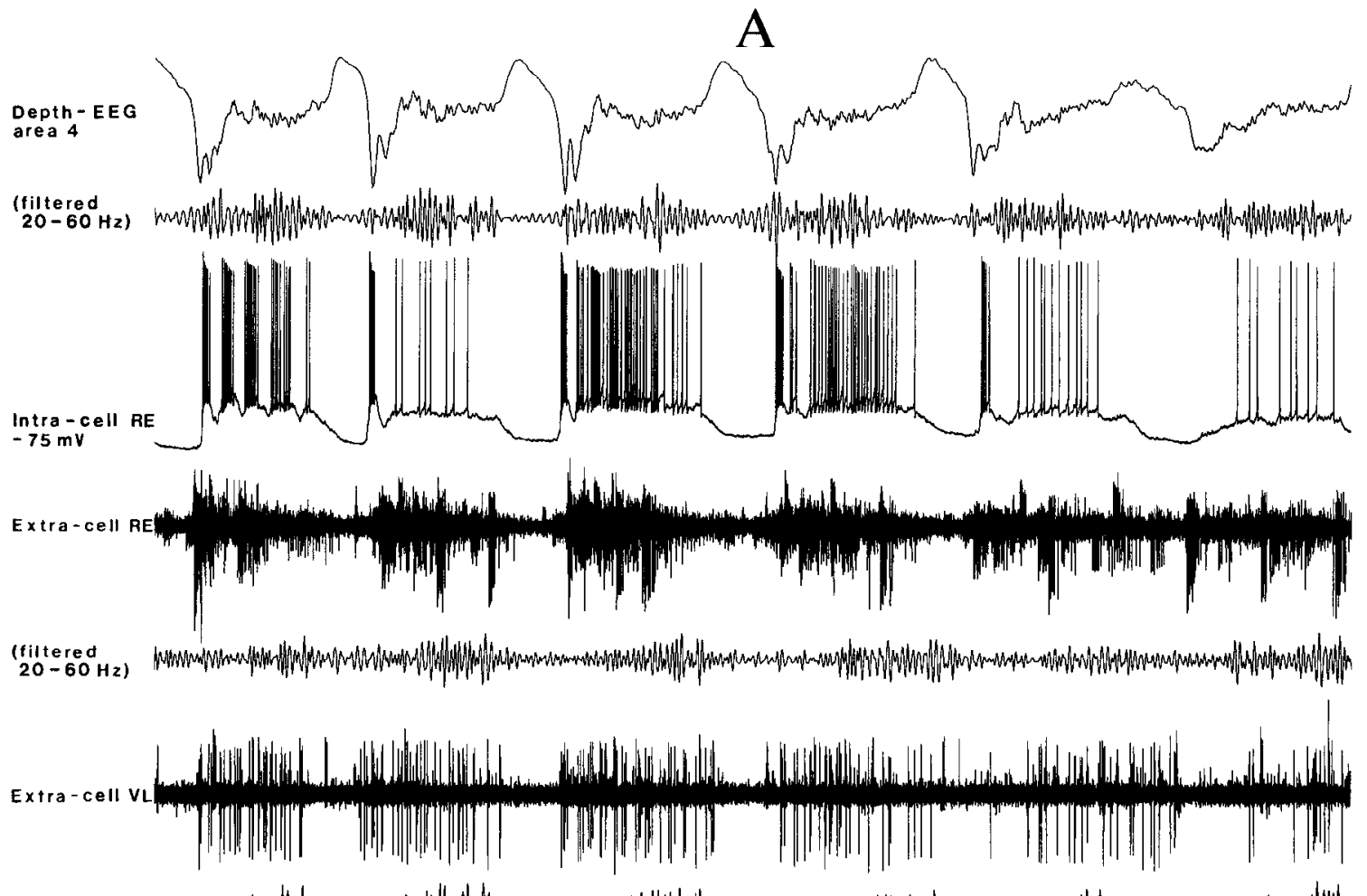

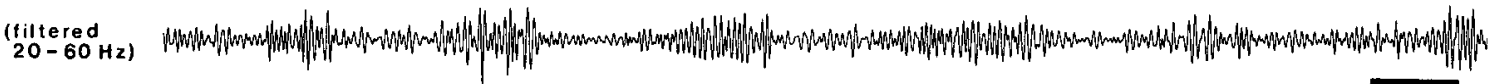

B

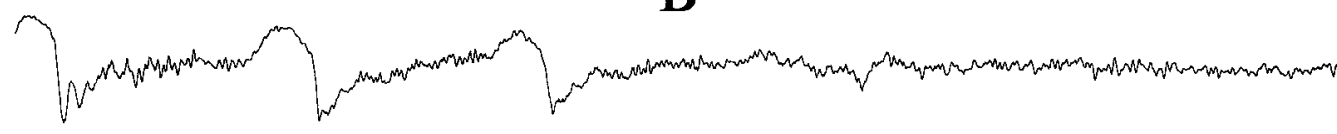

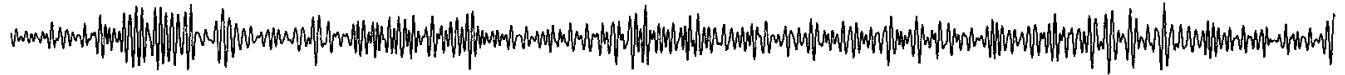

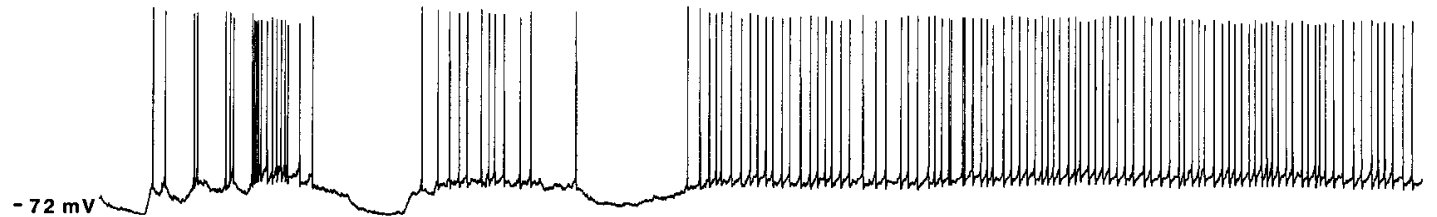

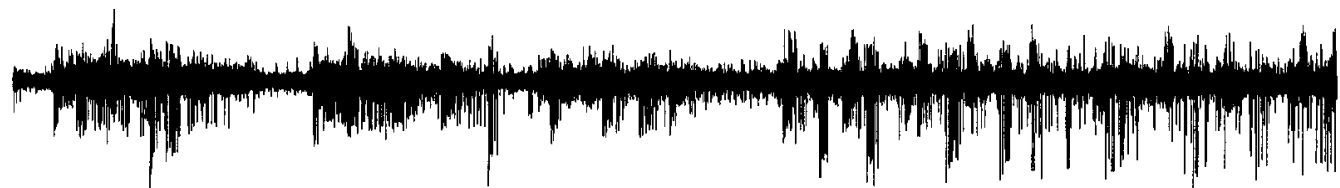

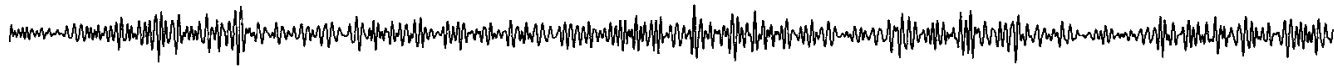

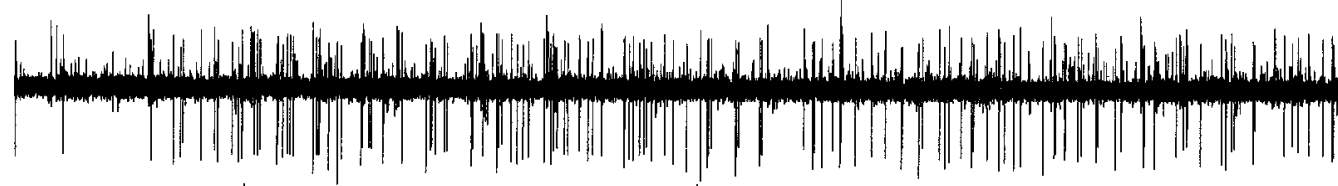

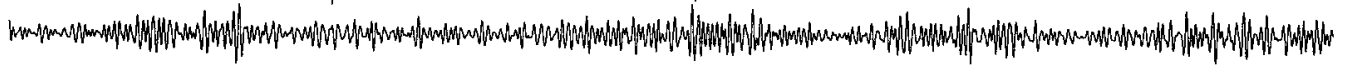

Figure 8. Synchronous sequences of fast waves in motor cortex, peri-VL sector of RE nuclear complex, and VL nucleus; ketamine and xylazine anesthesia. $A$, Simultaneous recordings of depth-EEG waves from area 4 , intracellular activity of $\mathrm{RE}$ cell from the rostrolateral district, extracellular multi-unit activity picked up by a microwire $2 \mathrm{~mm}$ apart from the intracellular micropipette, and extracellular recording of VL neurons. Below each of three extracellular traces are filtered activities $(20-60 \mathrm{~Hz}) . B$, Same recordings during a period leading to short activation. 

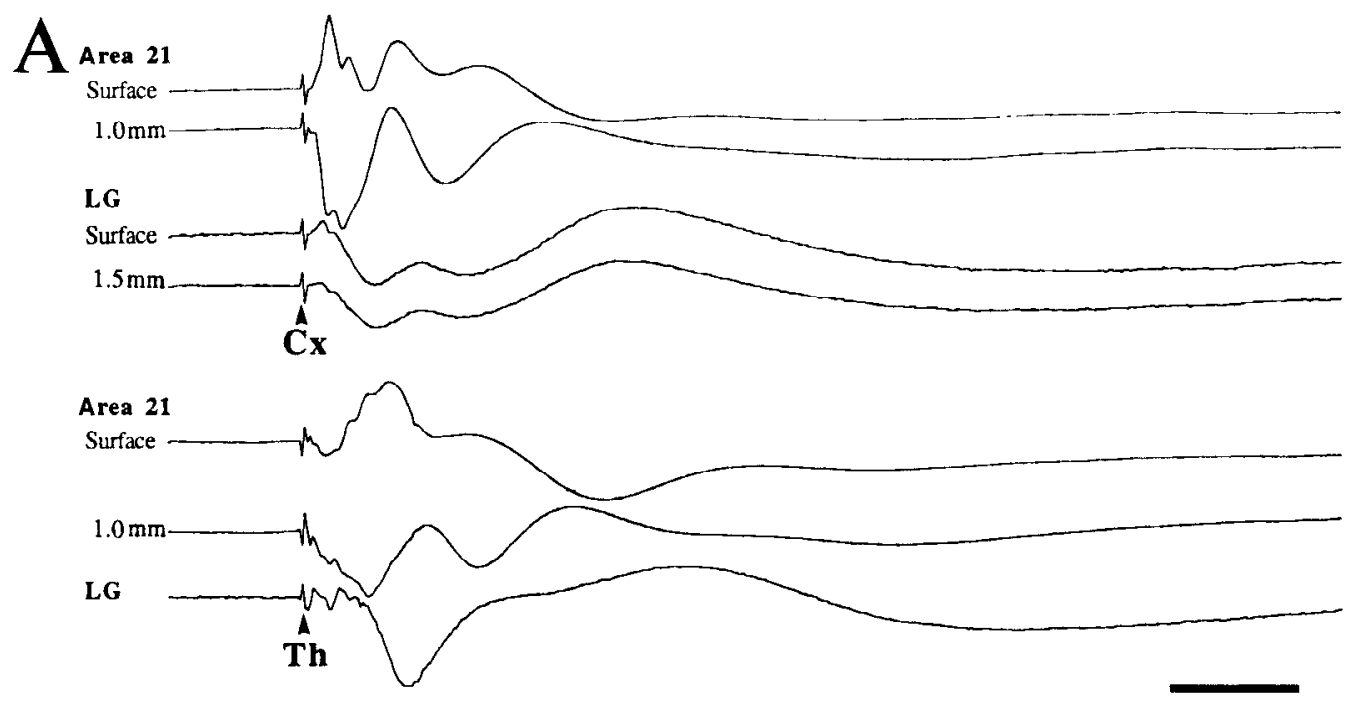

$10 \mathrm{~ms}$

B Area 21

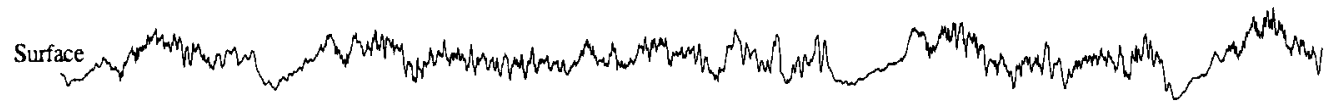

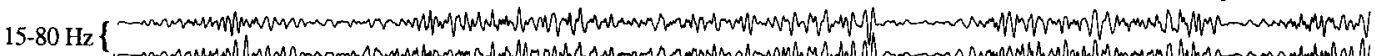

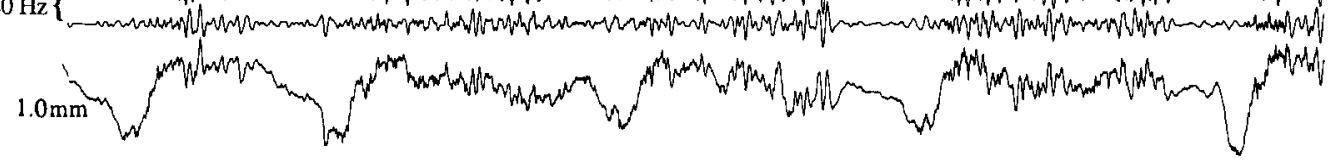

LG
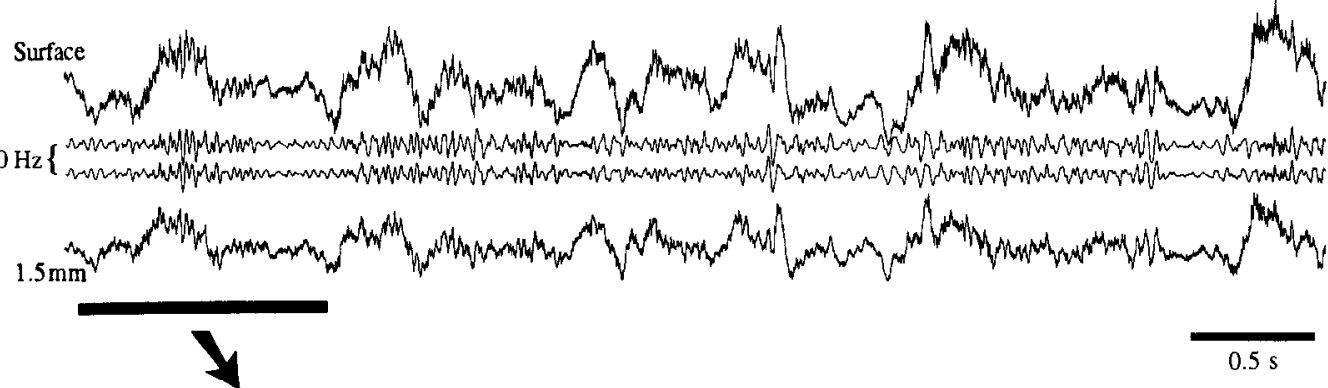

Cx-

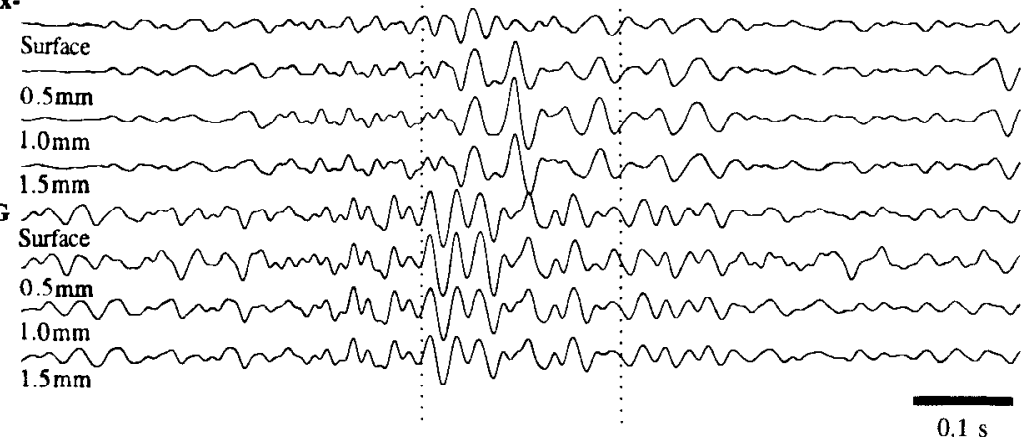

\section{CROSS CX-LG}

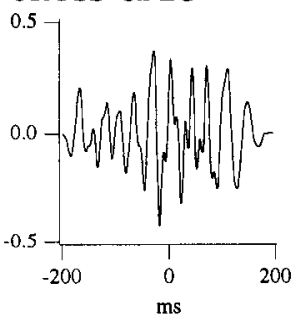

Figure 9. Correlated fast oscillations $(35-40 \mathrm{~Hz})$ of field potentials in reciprocally related cortical and thalamic foci; ketamine and xylazine anesthesia. $A$, Physiological identification of reciprocal projections between posterior suprasylvian area 21 and thalamic LG nucleus. One cortical $(C x)$ electrode and onc thalamic (Th) electrode (cach from the four-electrode arrays inscrted in cortcx and thalamus) wcre used to stimulate (arrowhead) and evoke field potentials in both cortex (surface and $1 \mathrm{~mm}$ depth) and thalamus (dorsal aspect of LG nucleus and $1.5 \mathrm{~mm}$ deeper). Cortical and thalamic multi-phasic field potentials were initiated with a latency $<1.5 \mathrm{msec}$, thus indicating monosynaptic responses. $B$, Simultaneous recording of spontaneous activities from four cortical (surface and $0.5,1$, and $1.5 \mathrm{~mm}$ depth) and four thalamic (dorsal surface of LG and $0.5,1.0$, and $1.5 \mathrm{~mm}$ deeper) foci that proved to be responsive in $A$. Filtered activities $(15-80 \mathrm{~Hz}$ ) are also illustrated between unfiltered traces (to simplify, only two cortical and two thalamic foci are depicted in the top panel of $B$ ). Filtered activities from period marked by horizontal bar are expanded below (arrow). Note oscillations at $35 \mathrm{~Hz}$ in cortex and at $40 \mathrm{~Hz}$ in thalamus. CROSS from windows, such as illustrated between dotted lines ( $C x$ at time 0 ), shows a time-lag of 3.5-4.0 msec between cortex and thalamus and higher frequencies in LG. 

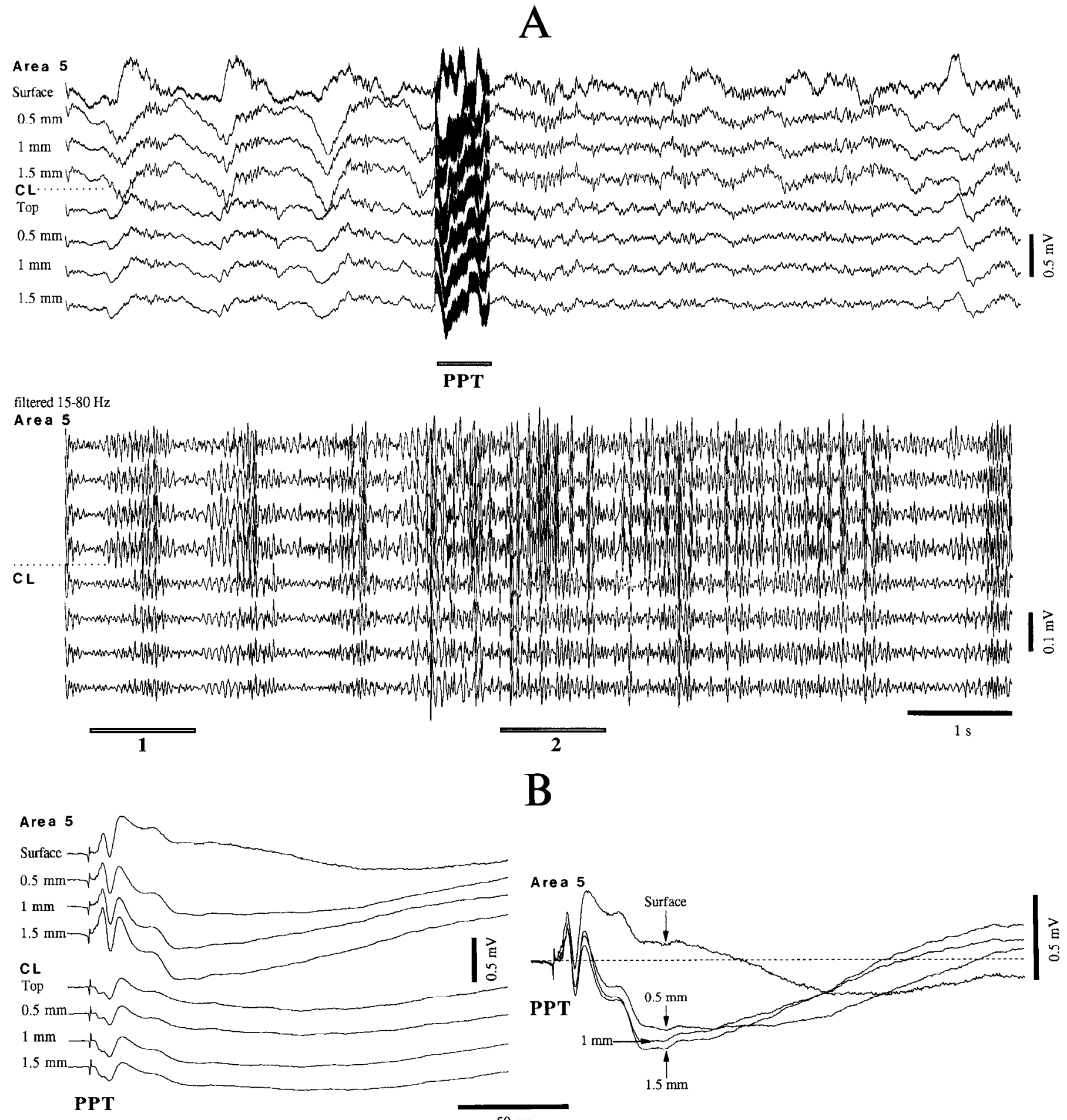

Figure 10. Brainstem PPT stimulation suppresses the slow oscillation and induces sustained fast oscillations; ketamine and xylazine anesthesia. $A$, Simultaneous recordings of field potentials in cortical suprasylvian area 5 (four electrodes at the surface, $0.5,1.0$, and $1.5 \mathrm{~mm}$ depth) and thalamic $\mathrm{CL}$ nucleus (four electrodes at the dorsal aspect of nucleus, $0.5,1.0$, and $1.5 \mathrm{~mm}$ deeper). PPT stimulation (horizontal bar) was a pulse-train at $300 \mathrm{~Hz}$, lasting for $0.5 \mathrm{sec}$. Below, same activities were filtered between 15 and $80 \mathrm{~Hz}$. Parts marked by 1 and 2 are expanded and analyzed in Figure 11. B, Responses evoked by single-shock to PPT nucleus in area 5 and CL nucleus. At right, superficial and deep cortical responses are superimposed, with increased amplitudes.

\section{Slow and fast EEG rhythms during natural sleep and wake states}

In chronic experiments, the slow oscillation displayed remarkable similarities to the slow oscillation recorded under ketamine- xylazine anesthesia, and the fast rhythms were diminished similarly or abolished during the depth-positive cortical EEG waves, corresponding to the hyperpolarization of cortical and thalamic neurons (Fig. 1B). Simultaneous recordings of field potentials in 

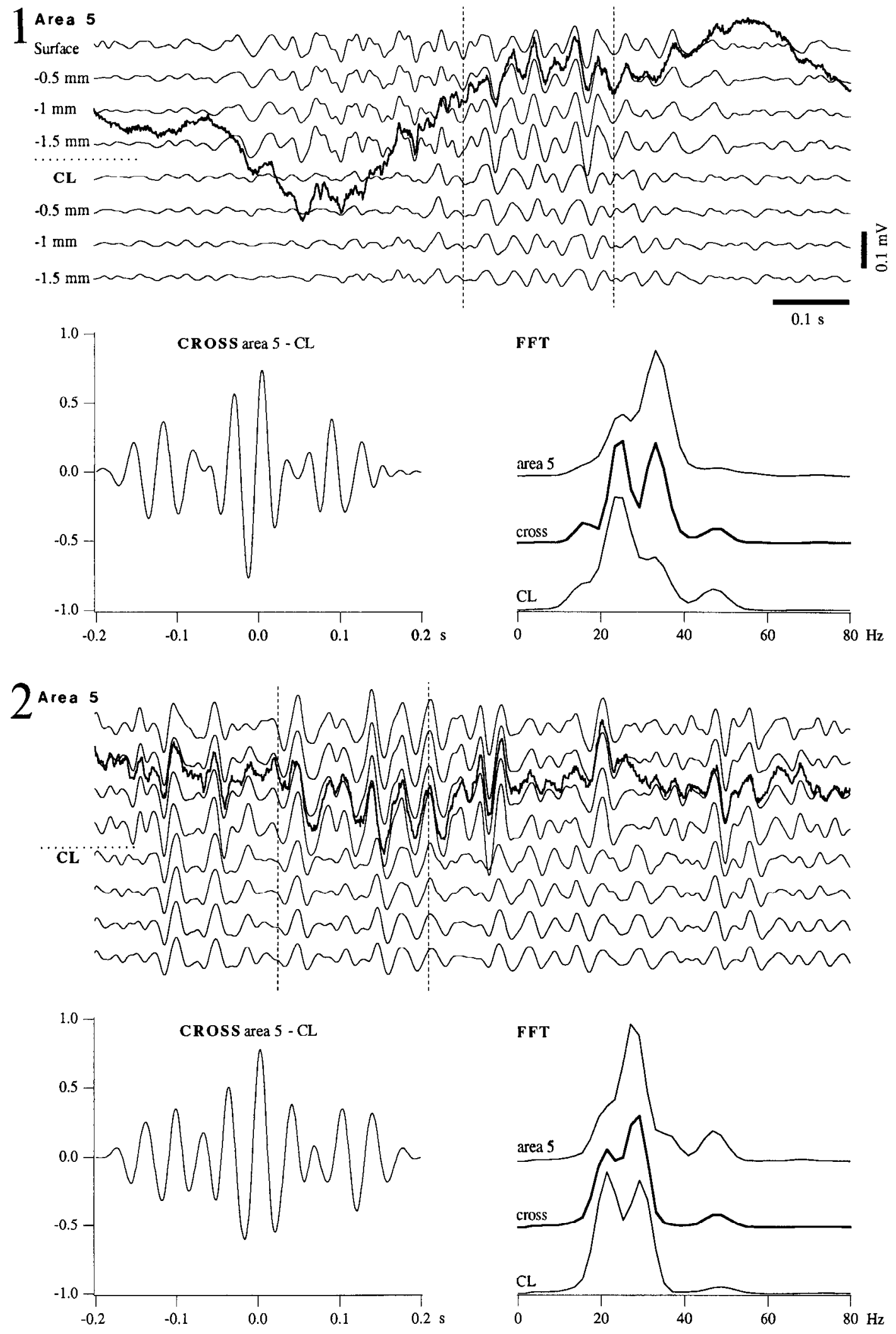

Figure 11. Analyses of epochs $I$ and 2 from Figure 10A. Part 1 is from a slowly oscillating epoch. Cortical and thalamic CL activities are filtered between 15 and $80 \mathrm{~Hz}$. The thick trace is one of the depth activities, unfiltered. Fast rhythms $(20-30 \mathrm{~Hz})$ are suppressed at the extreme left and right parts, corresponding to the long-lasting, surface-negative (depth-positive) wave of the slow oscillation $(A)$. CROSS between area 5 and CL activities show correlated activities, with short time-lags $(5-6 \mathrm{msec})$. FFT shows two equal peaks at $20 \mathrm{~Hz}$ and $30 \mathrm{~Hz}$ in the cross-spectrum. Part 2 is from the activated period elicited by PPT stimulation. Thick trace is unfiltered. In this epoch, fast rhythms are continuous, the CROSS is more regular, and cross-spectrum in FFT demonstrates a peak at $30 \mathrm{~Hz}$, higher than the peak at $20 \mathrm{~Hz}$. 

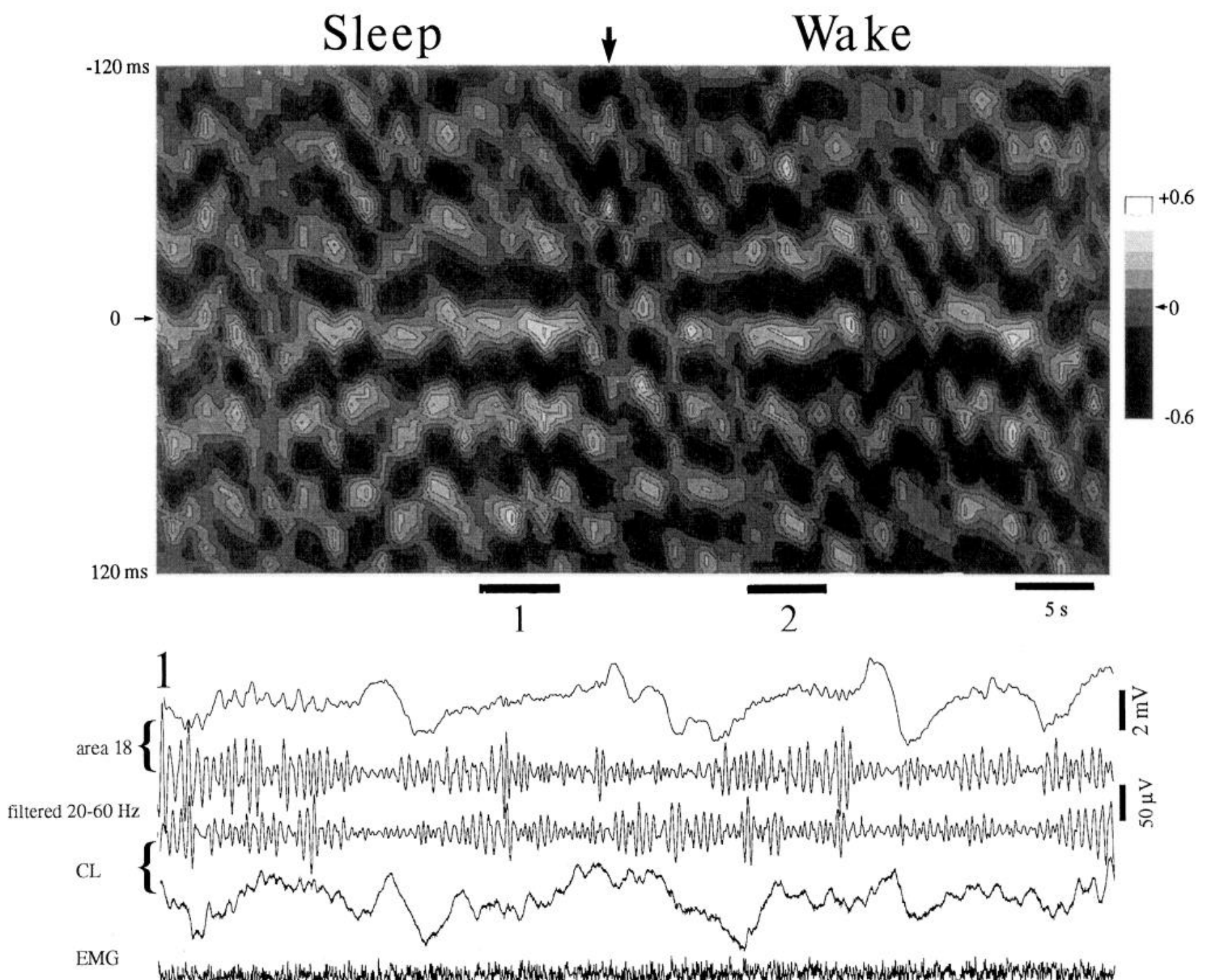

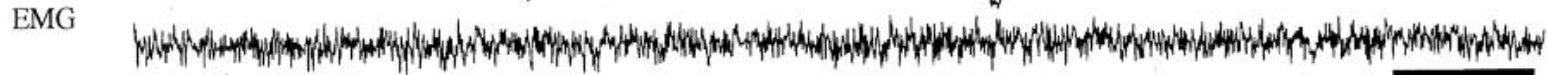

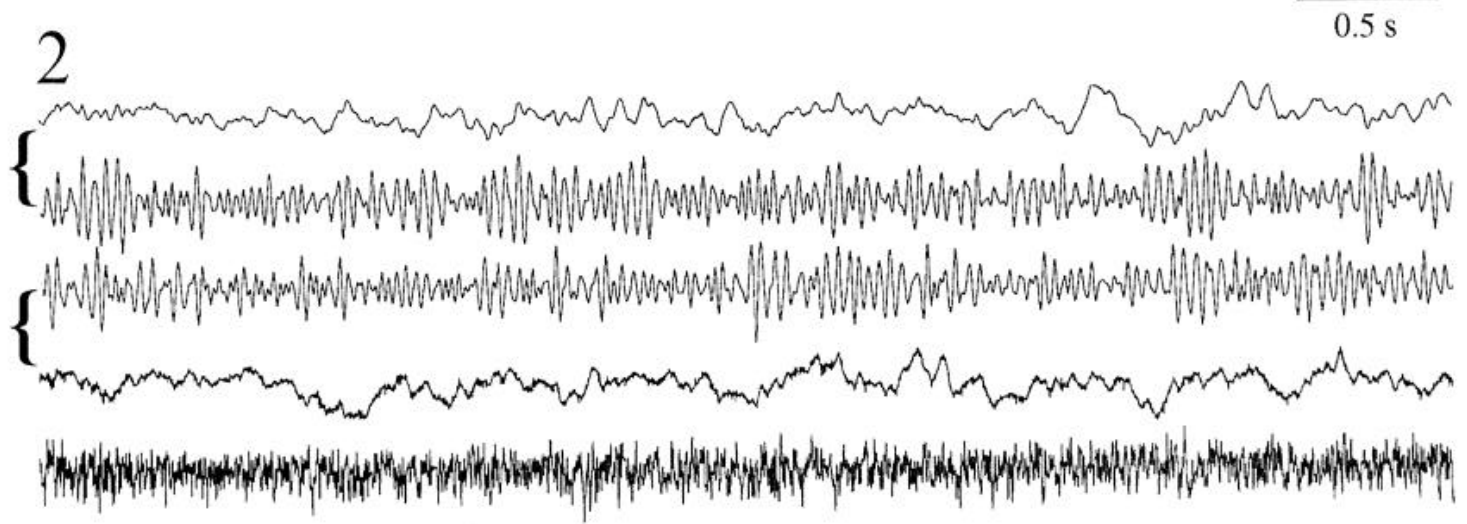

Figure 12. During sleep and wakefulness, fast oscillations $(25 \mathrm{~Hz})$ in cortical area 18 are correlated with fast oscillations at a similar frequency in rostral intralaminar CL thalamic nucleus; chronically implanted animal. Top panel depicts a period of arousal from sleep (arrow), with contour map representing sequential cross-correlations between filtered $(20-60 \mathrm{~Hz})$ field potentials from the depth of area 18 and CL nucleus. Note synchrony of fast rhythms (25 $\mathrm{Hz}$ ) during both sleep and waking. At right, gray scale calibration bar for the cross-correlations. The epochs marked by two horizontal bars ( 1 and 2 ) are taken from periods depicted with raw data in the bottom panel: field potentials from area 18 and CL nucleus (below and above these traces are filtered activities between 20 and $60 \mathrm{~Hz}$ ) and EMG activity.

the depth of neocortical areas and within appropriate dorsal thalamic nuclei, such as areas 4 or 18 and rostral intralaminar CL nucleus, showed concomitant sequences of waxing and waning fast oscillations at $20-40 \mathrm{~Hz}$, during both resting sleep and behavioral wakefulness (Fig. 12). Correlation and spectral techniques, resulting in topograms (or contour maps) illustrating the sequential relations between field potentials, revealed in-phase fast oscillations $(\sim 25 \mathrm{~Hz})$ between cortical and thalamic potentials during 
both resting sleep and the subsequent period of behavioral arousal (Fig. 12).

The study of evolutive oscillatory activities in cortex and thalamus during natural transitions from wake to sleep behavioral states (Fig. 13) indicated that (1) arousal from sleep was associated with the disappearance of low-frequency oscillations $(<15$ $\mathrm{Hz}$ ) and the appearance of fast rhythms in cortex as well as the thalamus; (2) the frequency of fast oscillations reached $40-45 \mathrm{~Hz}$ in cortex, while it was lower $(25-30 \mathrm{~Hz})$ in the thalamus, and fast rhythms occurred with a time-lag compared with their appearance at the cortical level (bottom right in Fig. 13); and (3) the first electrographic signs during the transition from waking to sleep were those of slow and spindle oscillations, whereas $\delta$ activity (1-4 $\mathrm{Hz}$ ) appeared in later stages of resting sleep.

\section{DISCUSSION}

This study demonstrates that spontaneously occurring fast oscillations (mainly $30-40 \mathrm{~Hz}$ ) are synchronized among different thalamic foci as well as between the thalamus and neocortex. Our data show that (1) fast oscillations occur during the depolarizing component of the slow sleep oscillation $(<1 \mathrm{~Hz})$, whereas they are suppressed during the long-lasting hyperpolarizing phase, in both thalamic and cortical cells; (2) the fast activity of TC cells consists of rhythmic EPSPs and/or short-lasting IPSPs; (3) robust coherence exists between fast waves from the cortical depth and subthreshold EPSPs of TC cells; (4) the synchronization of fast rhythms is best seen when reciprocal connections of thalamic and cortical neuronal pools are identified by monosynaptic responses in both directions; and (4) transient fast rhythms in thalamic neurons, dependent on the depolarizing phase of the slow sleep oscillation, become sustained upon stimulation of mesopontine cholinergic nuclei and during natural states of waking and REM sleep in behaving animals.

\section{Dependency of fast oscillations on the depolarizing phase of the slow oscillation: intrinsic properties and synaptic activities of thalamic neurons}

One of the major findings in this study is the demonstration that fast oscillations at $30-40 \mathrm{~Hz}$, generally regarded as characterizing states of brain arousal, also appear under deep anesthesia with ketamine-xylazine as well as during natural sleep. During these states, the fast rhythms are present selectively during the depolarizing phase of the slow sleep oscillation in both TC and RE neurons (Figs. 4-9). Our data are supported by the presence of fast $(\sim 40 \mathrm{~Hz})$ oscillations in the human EEG under ketamine anesthesia, when the subjects are not responsive and are unconscious (Plourde, 1995).

In TC cells, the fast rhythms that occur during the slow sleep oscillation are superimposed on a strong feedforward inhibition arising in GABAergic RE cells. This prevents the majority of TC neurons from discharging in response to fast oscillatory synaptic inputs of cortical origin. A small proportion of TC cells, however, discharge tonically during the depolarizing envelope of the slow oscillation (Fig. 6A), and if those cells were synchronized, they could have a great impact on cortical neurons. On the other hand, during periods of EEG activation, TC cells depolarize and approach firing threshold (Fig. 5, 2), thus enabling the corticothalamocortical loop to close for fast oscillations and to bring the thalamus into the concerted operations, which supposedly underlie information processing. In the rostral intralaminar CL nucleus, the depolarization-dependent spike-bursts of fast-conducting $(40-50 \mathrm{msec}) \mathrm{TC}$ cells, recurring rhythmically at $40 \mathrm{~Hz}$ during behavioral states of waking and REM sleep (Steriade et al., 1993b), may be imposed to widespread neocortical territories that in turn would drive back morphologically distant and functionally different thalamic nuclei.

The role played by RE neurons in the corticothalamic conjunction process underlying the synchronization of fast rhythms is less clear. In rats under urethane anesthesia, the $40-\mathrm{Hz}$ rhythm of RE cells was regarded as intrinsic and dependent on a pacemaker mechanism, because the subthreshold fast activity was voltagedependent, appeared at fixed frequencies, was not driven by synaptic inputs, and was not correlated with the activity of other thalamic nuclei and EEG (Pinault and Deschênes, 1992). At variance, other intracellular studies reported that the examination of the frequency versus current injected did not reveal any preferred frequency of RE cells between 10 and $400 \mathrm{~Hz}$ (Bal and McCormick, 1993), that the frequency of fast rhythms in these neurons depended on the amount of the injected depolarizing current, and that no subthreshold rhythmic activity at fixed frequencies could be detected (Contreras et al., 1992). The present data show that fast oscillations $(20-60 \mathrm{~Hz})$ of RE cells appear in grouped sequences, which are coherent with similar rhythms in dorsal thalamic nuclei and EEG (Fig. 8). Thus, rather than being an intrinsic activity attributable to presumed pacemaker properties, the fast oscillations in RE cells seem to result from network operations in interacting thalamic and neocortical neurons. The hypothesis that RE neurons display fast oscillations during selective attention or focused arousal was not confirmed in experimental studies on behaving animals. In contrast to the fast oscillations in cortical-projecting nuclei in both sleep and waking states (Figs. $12,13)$, fast rhythms were searched within different sectors of the RE nuclear complex in attentive, pcrforming animals, but their presence was denied (Canu and Rougeul, 1992; Bekisz and Wróbel, 1993).

The intrinsic fast oscillations in cortical neurons are generated by a voltage-dependent persistent $\mathrm{Na}^{+}$current, with the involvement of a delayed rectifier (Llinás et al., 1991). Notwithstanding the repeated demonstrations of intrinsic fast oscillations in thalamic and cortical neurons (Steriade et al., 1991, 1993b, 1996; Nuñez et al., 1992b; McCormick et al., 1993; Amitai, 1994; Gutfreund et al., 1995), the sensory-elicited and spontaneous fast rhythms occur as a result of combined intrinsic and synaptic activities in both neocortex (Jagadeesh et al., 1992; Steriade et al., 1996) and hippocampus, with a decisive participation of localcircuit inhibitory neurons (Buzsáki et al., 1983; Bragin et al., 1995; Buzsáki and Chrobak, 1995; Traub et al., in press). In hippocampal slices, the synchronized $40-\mathrm{Hz}$ rhythm may occur in the absence of fast glutamatergic transmission, through interactive inhibitory interneurons driven by metabotropic receptor activation and inducing fast oscillations in pyramidal cells through $\mathrm{GABA}_{\mathrm{A}}$ synapses (Whittington et al., 1995). Simulation studies of neocortical cells also revealed the mechanisms whereby IPSPs, presumably mediated by $\mathrm{GABA}_{\mathrm{A}}$ receptors, can phase-lock and entrain pyramidal neurons at frequencies between $\sim 35$ and $50 \mathrm{~Hz}$ (Lytton and Sejnowski, 1991).

In the present study, fast $(\sim 40 \mathrm{~Hz})$, short-lasting IPSPs were detected in TC cells during activated epochs, at relatively depolarized $V_{\mathrm{m}}$ levels (Fig. 4A) (Pinault and Deschênes, 1992). The origin of fast-recurring IPSPs may be ascribed to local interneurons and/or RE cells. The durations of IPSPs, which should be short enough for entraining fast oscillations in TC neurons, are strongly modulated by the behavioral state. As yet, there is no information about fluctuations in responsiveness of identified 


\section{A}

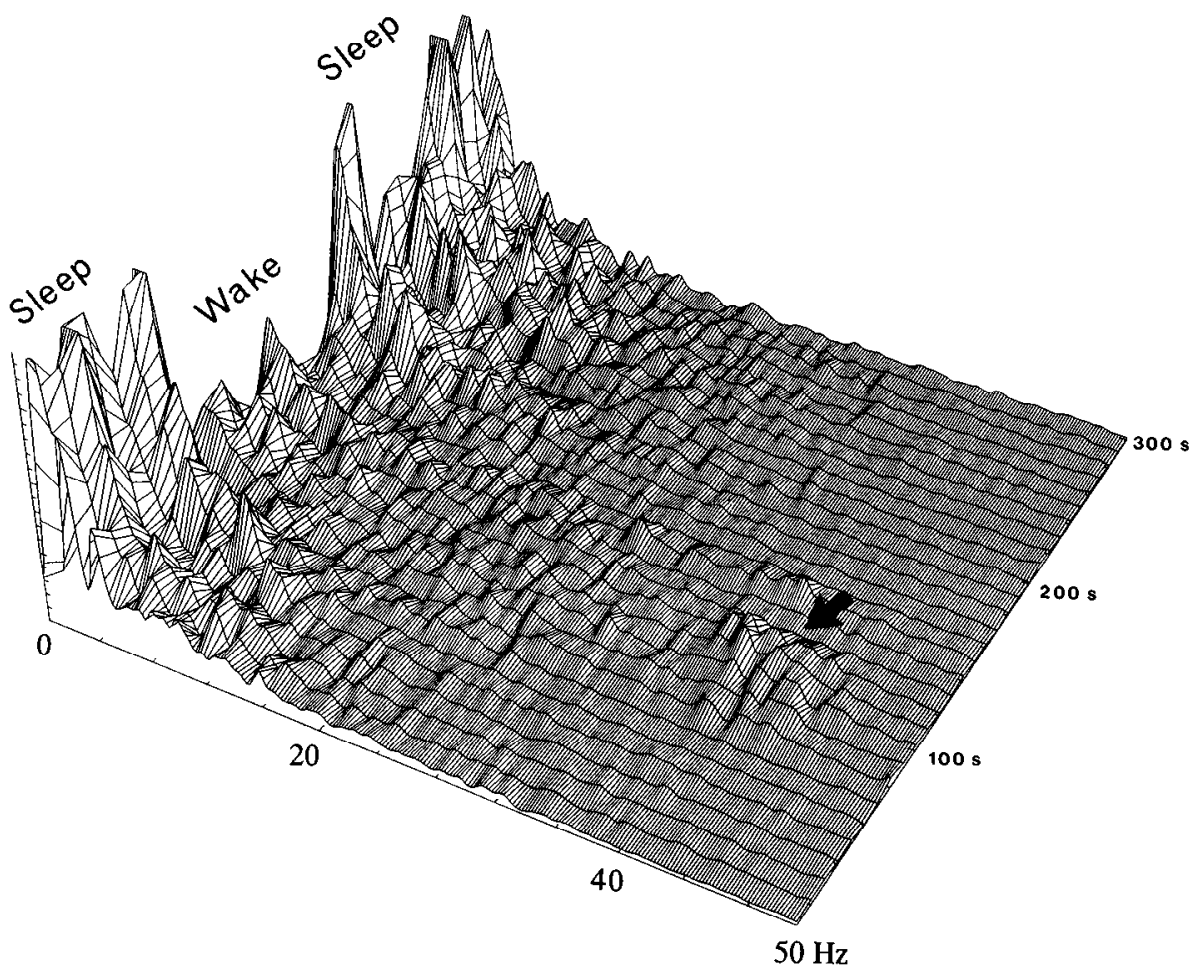

$0-1 \mathrm{~Hz}$

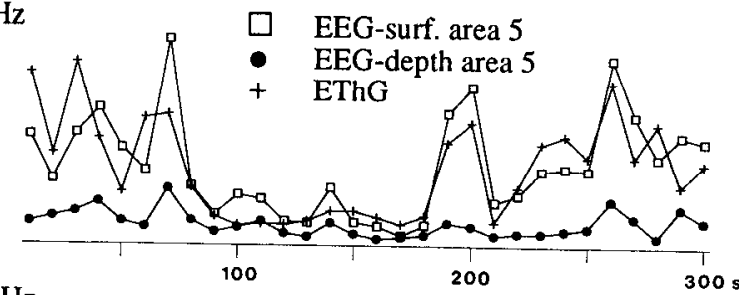

$1-4 \mathrm{~Hz}$

$4-15 \mathrm{~Hz}$

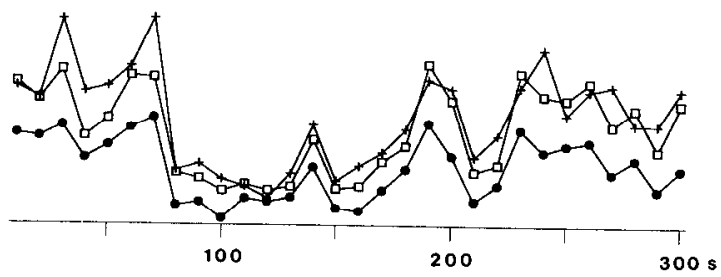

$20-50 \mathrm{~Hz}$
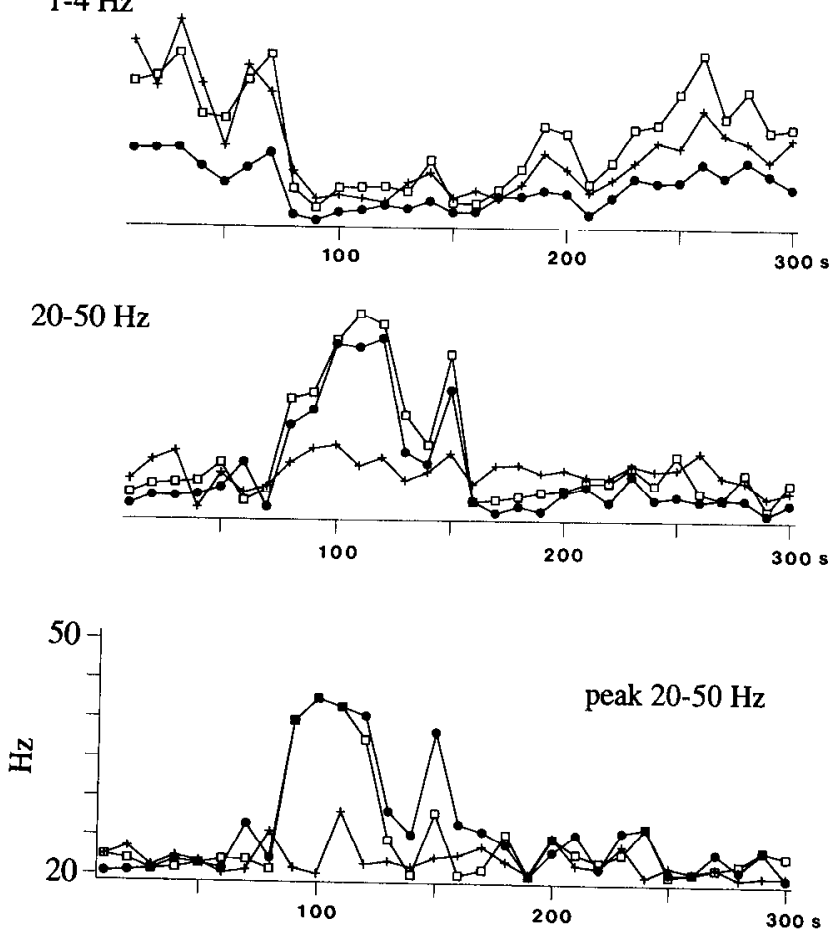

Figure 13. Sequential spectral analysis of EEG waves recorded from the surface and depth of cortical area 5 as well as from the lateroposterior thalamus $(E T h C)$ during transitions from natural slccp to waking and back to slccp; chronically implanted animal. $A$, Three-dimensional surface built up by successive FFTs of $10 \mathrm{sec}$ sequential windows. Natural sleep epochs are characterized by presence of high peaks in the range of slow oscillation, whereas arousal is accompanied by the appearance of a hump $\sim 40 \mathrm{~Hz}$ (arrow) and by diminution of low-frequency components. Note that the period with fast rhythms closely follows arousal, but does not last throughout the wake state. $B$, Spectral areas split in different frequency bands from surface- and depth-EEG and EThG. Same $300 \mathrm{sec}$ period as in $A$. Each point in graphs corresponds to the area within the indicated spectra (symbols). Arousal occurred at time 70-75 sec on the abscissa. The evolution of rhythms shows a general tendency of the three leads (two cortical and EThG) in all frequency bands, however less for the EThG in $0-1 \mathrm{~Hz}$ and $20-50 \mathrm{~Hz}$ bands (lower values are attributable to less ample waves). Frequencies from 0 to $15 \mathrm{~Hz}$ tend to disappear upon awakening. Slow oscillations in the $0-1 \mathrm{~Hz}$ band display steep suppression and onset. $\delta$ waves $(1-4 \mathrm{~Hz})$ also disappear upon arousal and tend to reappear after spindles (included in the band of $4-15 \mathrm{~Hz}$ ) that display a definite peak at time 140 sec. Arousal is associated with a huge increase in the power spectrum of the $20-50 \mathrm{~Hz}$ band of cortical EEG, whereas the EThG waves lagged cortical fast activities. The peak frequencies detected within the fast frequency range $(20-50 \mathrm{~Hz})$ in FFTs are plotted below and show a dominant oscillation reaching $40 \mathrm{~Hz}$. 
local-circuit thalamic cells during natural states of vigilance. In acute experiments, brain activation elicited by stimulation of mesopontine PPT/LDT cholinergic nuclei results in a drastically shortened duration of IPSPs in TC cells (Hu et al., 1989) while preserving and even enhancing the earliest component of the IPSP, which has a very fast onset and short duration (Curró Dossi et al., 1992) and is attributed to intraglomerular, dendro-dendritic inhibitory outputs of local-circuit cells (Paré et al., 1991). The subsequent biphasic sequence of $\mathrm{GABA}_{\mathrm{A} / \mathrm{B}}$ IPSPs (Crunelli et al., 1988), ascribed to the axonal firing of interneurons in nuclei that are naturally devoid of RE inputs (Paré et al., 1991), is diminished or suppressed upon brainstem cholinergic arousal (Curró Dossi et al., 1992), because of the action of acetylcholine on thalamic local interneurons (McCormick and Pape, 1988; Pape and McCormick, 1995). As to the GABAergic RE cells, they may produce short lasting IPSPs in TC cells, but only during brain-activated states, when they discharge tonically, with single action potentials (Steriade et al., 1986). During resting sleep, the prolonged spike-bursts of RE neurons (Domich et al., 1986; Steriade et al., 1986) induce long-lasting IPSPS in TC cells. This was first demonstrated by the transformation of prolonged IPSPs into short IPSPS after disconncction of TC cclls from the RE inputs (Steriade et al., 1985) and is also shown in the present experiments by using intracellular recordings of TC cells simultaneously with extracellular recordings of bursting RE cells (Fig. 5). Obviously, such prolonged IPSPs cannot account for fast oscillations in TC neurons. Although the projections of RE cells onto local interneurons in dorsal thalamic nuclei are less massive than those onto TC cells (Liu et al., 1995), the RE-to-interneuron connections probably result in disinhibitory effects at the level of TC cells (Steriade et al., 1985); however, these actions are not yet elucidated through direct dual recordings of these two types of thalamic inhibitory cells.

\section{Synchronization of fast oscillations in intrathalamic and TC networks}

The above evidence that both TC and RE cells display fast oscillations docs not indicate by itself the presence of intrathalamic synchronization, nor does it demonstrate the synchronization among thalamic and cortical neurons within the frequency range of fast rhythms.

Our data provide positive answers to these fundamental issues, by means of simultaneous recordings of field potentials, extracellular discharges, and intracellular activities from sensory, motor, intralaminar, and RE thalamic nuclei, combined with field potentials and intracellular recordings from related neocortical areas. These multi-site recordings show (1) intrathalamic synchrony within the VP (Figs. 2-3) and LG (Fig. 9B) thalamic nuclei; (2) TC synchrony between the LG nucleus and cortical projection areas (Fig. $9 B$ ) and between intracellularly recorded EPSPs of VL neurons and field potentials in motor cortex (Fig. 5), as well as between the CL intralaminar nucleus and the association suprasylvian area 5 (Figs. 10-11); and (3) grouped sequences of coherent fast rhythms in cortical area 4 , VL nucleus, and the peri-VL sector of RE nucleus (Fig. 8). Other experiments reported that a small proportion of neurons recorded from the medial posterior thalamic nucleus are synchronized with fast parietal cortical waves (Canu et al., 1994). We emphasize that the synchronization of fast oscillations became evident when recordings were made from thalamic and cortical foci whose reciprocal connections were identified by means of evoked responses in the ascending and descending projections (Fig. $9 A$ ). This indicates that similarly to the spatially restricted synchronization of fast oscillations in corticocortical networks (Steriade et al., 1996), the TC synchronization of fast oscillations is generally confined within systems that are well defined in terms of connectivity and functional significance. Such a spatial distribution contrasts with the widespread synchronization of low-frequency $(<15 \mathrm{~Hz})$ sleep rhythms in intracortical and corticothalamic networks (Amzica and Steriade, 1995a,b).

What are the connectivity features and mechanisms that underlie the intrathalamic synchronization within different nuclear groups such as VP (Figs. 2-3) and LG (Fig. 9B)? We have discussed above the differential role of local inhibitory interneurons and RE neurons. Although the $\mathrm{TC}$ cells of $\mathrm{LG}$ nucleus possess recurrent axonal collaterals (Friedländer et al., 1981) that may excite relay cells within the same nucleus (Nuñez et al., 1992a; Soltesz and Crunelli, 1992), there are no intra-VP connections mediated by axonal collaterals of TC cells (Yen and Jones, 1983). Thus, the synchronization among various VP foci hypothetically calls upon the thalamocorticothalamic loop, with just one interposed synapse in the cortex, or activities distributed at multiple levels including the brainstem relay stations, as described for oscillations at 10 to $12 \mathrm{~Hz}$ in the interconnected neuronal network of the somatosensory system (Nicolelis et al., 1995).

The synchronization of fast oscillations within specific TC systems is probably based on the reciprocal projections between relay nuclei and cerebral cortex. In addition to pathways linking primary neocortical areas to specific thalamic relay nuclei, largerscale synchronization may result from the fact that the corticothalamocortical loop returns not only to the same cortical area but also to distant fields, such as the cortico-LG and corticolateroposterior pathways, whose thalamic targets project in turn to the lateral suprasylvian area (Kato, 1990).

The hypothesis that the massive corticothalamic projection arising in layer VI controls the gain of sensory pathways to relay thalamic nuclei and that near-simultaneous activations of prethalamic and cortical inputs would transiently enhance the responses of TC neurons (Koch, 1987) was recently expanded to include the specificity of synchronization fealures among cortical and thalamic neurons. In anesthetized cats, the cortical feedback induces correlated firing in those groups of LG relay cells whose receptive field alignments are appropriate to the particular orientation discharges of cortical cells, thus providing a looped influence that enhances the effect of convergent LG inputs to visual cortex and locks the ensemble onto the stimulus (Sillito et al., 1994). These results are in line with the postulate that synchronization of activities evoked by a stimulus may subserve the perceptual integration in the visual system (Eckhorn et al., 1988; Gray ct al., 1989), but they enlarge this concept by indicating that one component of the underlying mechanism is the corticothalamic feedback. The widespread coherence of cortical fast oscillations at the magnetoencephalographic level was ascribed to the involvement of thalamic intralaminar nuclei (Llinás and Ribary, 1993). In behaving primates, the stimulus-specific fast oscillations $(50-90$ $\mathrm{Hz}$ ) in striate (V1) and extrastriate (V2) cortices, occurring with an unexpected V1-V2 phase difference near zero, were tentatively ascribed to common oscillatory inputs, some of them arising in the thalamus (Frien et al., 1994). In other experimental paradigms, cats were trained to perform visual or acoustic discrimination tasks correctly, with the result that oscillations $\sim 20 \mathrm{~Hz}$ appeared simultaneously in the visual cortex and LG nucleus during visual attention, but were rarely found at the same sites when the animal made an error or during acoustic trials (Wróbel et al., 1994). It 
must be emphasized that in those experiments, the occurrence of fast rhythms by a stimulus-dependent mechanism was ruled out. Thus, in such instances, the oscillations are attributable to an increased level of alertness that is specific to the visual system, probably in a way similar to the appearance of fast rhythms over the sensorimotor cortex during highly motivated behavioral states (retrieving raisins from unseen locations) but less often during repetitive trained movements (Murthy and Fetz, 1992).

\section{Concluding remarks}

The view that fast oscillations are part of the spontaneous electrical activity during brain-activated states is supported by data showing that such fast rhythms in TC systems outlast the stimulation of brainstem ascending activating systems with generalized actions (Steriade, 1993). Stimulation of the specific pathway from the cerebellar interpositus nucleus to the VL nucleus and areas 4 and 6 results in fast oscillations confined within the limits of the motor TC system (Steriade, 1995). These results, obtained in acutely prepared animals under ketamine-xylazine anesthesia, are corroborated by data obtained in chronically implanted, behaving animals that demonstrate the synchronization of fast spontaneous rhythms in intracortical (Steriade et al., 1996) and corticothalamic (present data) networks. Importantly, the synchronized fast oscillations are present not only during the brain-active behavioral states of waking and REM sleep or during the brainstem-elicited generalized activation, but also during resting sleep or deep anesthesia when such rhythms are dependent on the depolarizing envelope of the slow sleep oscillation, whereas they are interrupted during the prolonged hyperpolarizations of cortical, RE, and TC cells. Thus, fast spontaneous oscillations are highly dependent on alertness, occurring tonically during brain-activated states and transiently during depolarization of cells in resting sleep or anesthesia.

The fact that contrary to the conventional wisdom, spontaneous fast oscillations $(30-40 \mathrm{~Hz})$ also appear during states of mental annihilation, such as deep anesthesia and resting sleep, does not preclude the possibility that the same intrinsic and network properties that underlie the fast oscillations during these states of unconsciousness would operate to underlie perceptual integration by synchronization when relevant stimuli occur in wakefulness. The subthreshold depolarizations at fast frequencies in neocortical and TC cells may bias these neurons to fire synchronously at fast frequencies when excitatory signals reach them (Lampl and Yarom, 1993), thus increasing the impact on neurons at subsequent relays. This mechanism may also be operative when synchronous brainstem-generated pontogeniculo-occipital (PGO) potentials are imposed, during REM sleep, on TC and cortical cells displaying subthreshold fast-depolarizing oscillations. Multisite recordings from cortical areas showed that PGO potentials display a progressive increase in the degree of synchronization throughout the state of REM sleep (Amzica and Steriade, 1996). Because bricf PPT stimuli clicit biphasic PGO-like potentials followed by synchronized fast oscillations at $30-40 \mathrm{~Hz}$ (Steriade et al., 1996), the widespread coherence of brainstemthalamocortical PGO potentials during REM sleep may underlie the synchronization of fast oscillations during dreaming sleep (Llinás and Ribary, 1993; Steriade et al., 1996).

\section{REFERENCES}

Amitai Y (1994) Membrane potential oscillations underlying firing patterns in neocortical neurons. Neuroscience 63:151-161.

Amzica F, Steriade M (1995a) Short- and long-range synchronization of the slow $(<1 \mathrm{~Hz})$ cortical oscillation. J Neurophysiol 73:20 - 38 .
Amzica F, Steriade M (1995b) Disconnection of intracortical synaptic linkages disrupts synchronization of a slow oscillation. J Neurosci 15:4658-4677.

Amzica F, Steriade M (1996) Progressive cortical synchronization of ponto-geniculo-occipital potentials during REM sleep. Neuroscience $72: 309-314$

Bal T, McCormick DA (1993) Mechanisms of oscillatory activity in guinea-pig nucleus reticularis thalami in vitro: a mammalian pacemaker. J Physiol (Lond) 466:669-691.

Bekisz M, Wróbel A (1993) $20 \mathrm{~Hz}$ rhythm of activity in visual system of perceiving cat. Acta Neurobiol Exp (Warsz) 53:175-182.

Bendat JS, Piersol AG (1980) Engineering applications of correlation and spectral analysis. New York: Wiley.

Bragin A, Jándo G, Nádasdy Z, Hetke J, Wise K, Buzsáki G (1995) Gramma $(40-100 \mathrm{~Hz})$ oscillation in the hippocampus of the behaving rat. J Neurosci 15:47-60.

Buzsáki G, Chrobak JJ (1995) Temporal structure in spatially organized ncuronal enscmblcs: a rolc for intcrncuron networks. Curr Opin Neurobiol 5:504-510.

Buzsáki G, Leung LWS, Vanderwolf CH (1983) Cellular bases of hippocampal EEG in the behaving rat. Brain Res Rev 6:139-171.

Canu MH, Rougeul A (1992) Nucleus reticularis thalami participates in sleep spindles, not in beta rhythms concomitant with attention in cat. C R Hebd Seances Acad Sci 315:513-520.

Canu MH, Buser P, Rougeul A (1994) Relationship between posterior thalamic nucleus unit activity and parietal cortical rhythms (heta) in the waking cat. Neuroscience 60:679-688.

Contreras D, Steriade M (1995) Cellular basis of EEG slow rhythms: a study of dynamic relationships. J Neurosci 15:604-622.

Contreras D, Curró Dossi R, Steriade M (1992) Bursting and tonic discharges in two classes of reticular thalamic neurones in vivo. J Neurophysiol 68:973-977.

Crunelli V, Haby M, Jassik-Gerschenfeld D, Leresche N, Pirchio M (1988) $\mathrm{Cl}^{-}$and $\mathrm{K}^{+}$-dependent inhibitory postsynaptic potentials evoked by interneurons of the rat lateral geniculate nucleus. J Physiol (Lond) 399:153-176.

Curró Dossi R, Paré D, Steriade M (1992) Various types of inhibitory postsynaptic potentials in anterior thalamic cells are differentially altered by stimulation of laterodorsal tegmental cholinergic nucleus. Neuroscience 47:279-289.

Domich L, Oakson G, Steriade M 1986 Thalamic burst patterns in the naturally sleeping cat: a comparison between cortically-projecting and reticularis neurones. J Physiol (Lond) 379:429-450.

Eckhorn R, Bauer R, Jordan W, Brosch M, Kruse W, Munk M, Reitboeck HJ (1988) Coherent oscillations: a mechanism of feature linking in the visual cortex? Biol Cybern 60:121-130.

Friedländer M, Lin CS, Stanford LR, Sherman SM (1981) Morphology of functionally identified neurons in the lateral geniculate nucleus of the cat. J Neurophysiol 46:80-129.

Frien A, Eckhorn R, Bauer R, Woelbern T, Kehr H (1994) Stimulusspecific fast oscillations at zero phase between visual areas $\mathrm{V} 1$ and $\mathrm{V} 2$ of awake monkey. NeuroReport 5:2273-2277.

Ghose GM, Freeman RD (1992) Oscillatory discharge in the visual system: does it have a functional role? J Neurophysiol 68:1558-1574.

Gilbert C, Kelly JP (1975) The projections of cells in different layers of the cat's visual cortex. J Comp Neurol 163:81-105.

Gray CM, König P, Engel AK, Singer W (1989) Stimulus-specific neuronal oscillations in cat visual cortex exhibit inter-columnar synchronization which reflects global stimulus properties. Nature 338:334-337.

Gutfreund Y, Yarom Y, Segev I (1995) Subthreshold oscillations and resonant frequency in guinea-pig cortical neurons: physiology and modelling. J Physiol (Lond) 483:621-640.

Hu B, Steriade M, Deschênes M (1989) The effects of brainstem peribrachial stimulation on neurons of the lateral geniculate nucleus. Neuroscience 31:13-24.

Jagadeesh B, Gray CM, Ferster D (1992) Visually evoked oscillations of membrane potential in cells of cat visual cortex. Science 257:552-554.

Jones EG (1985) The thalamus. New York: Plenum.

Kato N (1990) Cortico-thalamo-cortical projection between visual cortices. Brain Res 509:150-152.

Koch C (1987) The action of the corticothalamic pathway on sensory thalamic nuclei: a hypothesis. Neuroscience 23:399-406.

Lampl I, Yarom Y (1993) Subthreshold oscillations of the membrane potential: a functional synchronizing and timing device. J Neurophysiol $70: 2181-2186$. 
Lindström S, Wróbel A (1990) Frequency dependent corticofugal cxeitation of principal cells in the cat's dorsal lateral geniculate nucleus. Exp Brain Res 79:313-318.

Liu XB, Warren RA, Jones EG (1995) Synaptic distribution of afferents from reticular nucleus in ventroposterior nucleus of cat thalamus. J Comp Neurol 352:187-202.

Llinás R, Grace AA, Yarom Y (1991) In vitro neurons in mammalian cortical layer 4 exhibit intrinsic oscillatory activity in the $10-$ to $50-\mathrm{Hz}$ frequency range. Proc Natl Acad Sci USA 88:897-901.

Llinás R, Ribary U (1993) Coherent $40-\mathrm{Hz}$ oscillation characterizes dream states in humans. Proc Natl Acad Sci USA 90:2078-2081.

Llinás R, Ribary U, Joliot M, Wang XJ (1994) Content and context in temporal thalamocortical binding. In: Temporal coding in the brain (Buzsáki G, Llinás R, Singer W, Berthoz A, Christen Y, eds), pp 251-272. Berlin: Springer.

Lytton WW, Sejnowski TJ (1991) Simulations of cortical pyramidal neurons synchronized by inhibitory interneurons. J Neurophysiol 66:1059-1079.

McCormick DA, Pape HC (1988) Acetylcholine inhibits identified interneurons in the cat lateral geniculate nucleus. Nature 334:246-248.

McCormick DA, Gray C, Wang Z (1993) Chattering cells: a new physiological subtype which may contribute to $20-60 \mathrm{~Hz}$ oscillations in cat visual cortex. Soc Neurosci Abstr 19:869.

Murthy VN, Fetz EE (1992) Coherent $25-$ to $35-\mathrm{Hz}$ oscillations in the sensorimotor cortex of awake behaving monkeys. Proc Natl Acad Sci USA 89:5670-5674.

Nicolelis MAL, Baccala LA, Lin RCS, Chapin JK (1995) Sensorimotor encoding by synchronous neural ensemble activity at multiple levels of the somatosensory system. Science 268:1353-1358.

Nuñez A, Amzica F, Steriade M (1992a) Intrinsic and synaptically generated delta $(1-4 \mathrm{~Hz})$ rhythms in dorsal lateral geniculate neurons and their modulation by light-induced fast $(30-70 \mathrm{~Hz})$ events. Neuroscience $51: 269-284$

Nuñez A, Amzica F, Steriade M (1992b) Voltage-dependent fast (20-40 $\mathrm{Hz}$ ) oscillations in long-axoned neocortical neurons. Neuroscience 51:7-10.

Pape HC, McCormick DA (1995) Electrophysiological and pharmacological properties of interneurons in the cat dorsal lateral geniculate nucleus. Neuroscience 68:1105-1125.

Paré D, Curró Dossi R, Steriade M (1991) Three types of inhibitory postsynaptic potentials generated by interneurons in the anterior thalamic complex of cat. J Neurophysiol 66:1190-1204.

Paré D, Smith Y, Parent A, Steriade M (1988) Projections of brainstem core cholinergic and non-cholinergic neurons of cat to intralaminar and reticular thalamic nuclei. Neuroscience 25:69-86.

Pinault D, Deschênes M (1992) Voltage-dependent $40-\mathrm{Hz}$ oscillations in rat reticular thalamic neurons in vivo. Neuroscience 51:245-258.

Plourde G (1995) The effects of ketamine on gamma rhythms in humans. Soc Neurosci Abstr 21:451.

Raczkowski D, Rosenquist AC (1980) Connections of the parvocellular $C$ laminae of the dorsal lateral geniculate nucleus with the visual cortex in the cat. Brain Res 199:447-451.

Ribary U, Ioannides AA, Singh KD, Hasson R, Bolton JP, Lado F, Mogilner A, Llinás R (1991) Magnetic field tomography of coherent thalamocortical $40-\mathrm{Hz}$ oscillations in humans. Proc Natl Acad Sci USA 88:11037-11041.

Sherk H (1986) Location and connections of visual cortical areas in the cat's suprasylvian sulcus. J Comp Neurol 247:1-31.
Sillito A, Joncs HE, Gcrstcin GL, West DC (1994) Feature-linked synchronization of thalamic relay cell firing induced by feedback from the visual cortex. Nature 369:479-482.

Soltesz I, Crunelli V (1992) A role for low-frequency, rhythmic synaptic potentials in the synchronization of cat thalamocortical cells. J Physiol (Lond) 457:257-276.

Steriade M (1993) Central core modulation of spontaneous oscillations and sensory transmission in thalamocortical systems. Curr Opin Neurobiol 3:619-625.

Steriade M (1995) Two channels of the cerebello-thalamo-cortical system. J Comp Neurol 354:57-70.

Steriade M, Amzica F (1996) Intracortical and corticothalamic coherency of fast spontaneous oscillations. Proc Natl Acad Sci USA 93:2533-2538

Steriade M, Amzica F, Contreras D (1996) Synchronization of fast $(30-40 \mathrm{~Hz})$ spontaneous cortical rhythms during brain activation. J Neurosci 16:392-417.

Steriade M, Amzica F, Nuñez A (1993a) Cholinergic and noradrenergic modulation of the slow $(\approx 0.3 \mathrm{~Hz})$ oscillation in neocortical cells. $J$ Neurophysiol 70:1384-1400.

Steriade M, Contreras D, Amzica F (1994) Synchronized sleep oscillations and their paroxysmal developments. Trends Neurosci 17:199-208.

Steriade M, Curró Dossi R, Contreras D (1993b) Electrophysiolugicäl properties of intralaminar thalamocortical cells discharging rhythmic $(\approx 40 \mathrm{~Hz})$ spike-bursts at $\approx 1000 \mathrm{~Hz}$ during waking and rapid eye movement sleep. Neuroscience 56:1-9.

Steriade M, Curró Dossi R, Paré D, Oakson G (1991) Fast oscillations $(20-40 \mathrm{~Hz})$ in thalamocortical systems and their potentiation by mesopontine cholinergic nuclei in the cat. Proc Natl Acad Sci USA 88:4396-4400.

Steriade M, Datta S, Paré D, Oakson G, Curró Dossi R (1990) Neuronal activities in brainstem cholinergic nuclei related to tonic activation processes in thalamocortical systems. J Neurosci 10:2541-2559.

Steriade M, Deschênes M, Domich L, Mulle C (1985) Abolition of spindle oscillations in thalamic neurons disconnected from the nucleus reticularis thalami. J Neurophysiol 54:1473-1497.

Steriade M, Domich L, Oakson $G$ (1986) Reticularis thalamic neurons revisited: activity changes during shifts in states of vigilance. J Neurosci 6:68-81

Steriade M, Glenn LL (1982) Neocortical and caudate projections of intralaminar thalamic neurons and their synaptic excitation from the midbrain core. J Neurophysiol 48:352-371.

Tong L, Kalil RE, Spear PD (1982) Thalamic projections to visual areas of the middle suprasylvian sulcus in the cat. J Comp Neurol 212:103-117.

Traub RD, Buzsáki G, Jefferys JGR, Whittington MA, Colling SB, Penttonen M (1996) Analysis of gamma rhythms in the rat hippocampus in vitro and in vivo. J Physiol (Lond), in press.

Whittington MA, Traub RD, Jefferys JGR (1995) Synchronized oscillations in interneuron networks driven by metabotropic glutamate receptor activation. Nature 373:612-615.

Wróbel A, Bekisz M, Kublik E, Waleszczyk W (1994) $20 \mathrm{~Hz}$ bursting beta activity in the cortico-thalamic system of visually attending cats. Acta Neurobiol Exp (Warsz) 54:95-107.

Yen CT, Jones EG (1983) Intracellular staining of physiologically identified neurons and axons in the somatosensory thalamus of the cat. Brain Res 280:148-154. 